\title{
Recent Advancements in Crystalline Pb-Free Halide Double Perovskites
}

\author{
Muhammad Usman $\mathbb{D}$ and Qingfeng Yan * \\ Department of Chemistry, Tsinghua University, Beijing 100084, China; musman@chem.qau.edu.pk \\ * Correspondence: yanqf@mail.tsinghua.edu.cn
}

Received: 3 January 2020; Accepted: 21 January 2020; Published: 23 January 2020

\begin{abstract}
Lead halide perovskites have gained more and more attention because of their ease of synthesis and excellent photoelectric properties including a large absorption coefficient, long carrier lifetime, long carrier diffusion length, and high carrier mobility. However, their toxicity, instability, and phase degradation in ambient environments impede their large-scale applications. To address these concerns, it is desirable to find stable alternative halide perovskites without toxicity and with comparable optoelectronic properties to lead-based perovskites. Over the years, a considerable number of lead-free halide perovskites have been added to this family of materials, including $\mathrm{A}_{2} \mathrm{~B}^{\prime} \mathrm{B}^{\prime \prime} \mathrm{X}_{6}, \mathrm{~A}_{2} \mathrm{BX}_{6}$, and $\mathrm{A}_{3} \mathrm{~B}_{2} \mathrm{X}_{9}$ type perovskites. Among these, double perovskites with the general formula $\mathrm{A}_{2} \mathrm{~B}^{\prime} \mathrm{B}^{\prime \prime} \mathrm{X}_{6}$ are deemed to be a potential alternative to lead halide perovskites as they possess good stability under ambient conditions and excellent optoelectronic properties. In this review, recent progress in exploring $\mathrm{Pb}$-free halide double perovskites is highlighted. The synthesis, composition-tuning, physical properties, and applications of representative 3D, 2D, and nanocrystal $\mathrm{A}_{2} \mathrm{~B}^{\prime} \mathrm{B}^{\prime \prime} \mathrm{X}_{6}$ double perovskites are introduced. In addition, perspectives about current challenges and solutions in this field are also provided.
\end{abstract}

Keywords: halide perovskites; double perovskites; lead-free

\section{Introduction}

Lead halide perovskites with the general formula $\mathrm{APbX}$ where $\mathrm{A}=\mathrm{CH}_{3} \mathrm{NH}_{3}{ }^{+}(\mathrm{MA}), \mathrm{CH}\left(\mathrm{NH}_{2}\right)_{2}{ }^{+}$ (FA) or $\mathrm{Cs}^{+}$and $\mathrm{X}=\mathrm{Cl}^{-}, \mathrm{Br}^{-}$, or $\mathrm{I}^{-}$have emerged as a class of materials with promising photophysical properties in the last 10 years. They have shown superior potential in various applications like photodetectors, solar cells, light emitting diodes (LEDs), nuclear radiation detectors, optical fibers, lasers, and photocatalysts etc. [1-8]. Initially, lead-halide perovskite was used in dye-sensitized solar cells as an optical sensitizer with liquid electrolyte, and this solar cell showed low efficiency (3.8\%) [9]. In subsequent years, the effiapporciency of lead-based perovskite solar cells was improved and gained an intensive research focus around the world. So far, the power conversion efficiency (PCE) of perovskite solar cells has increased from 9\% in 2012 to $25.2 \%$ in 2019 [10-18].

The main drawbacks of these materials are their toxicity and instability under ambient conditions. Lead-based halide perovskites still dominate, though they appear to be non-satisfactory for large-scale application because of these drawbacks. Researchers have made a significant effort to search for less toxic and more stable alternative perovskites with good photophysical properties [19-21]. To reduce toxicity, efforts have been made which have started in the last few years to replace $\mathrm{Pb}$ with another divalent non-toxic metal cation while retaining the $\mathrm{ABX}_{3}$ structure. The group-IVA elements in the periodic table like $\mathrm{Sn}$ and Ge appear to be the most suitable alternatives for $\mathrm{Pb}$ in a perovskite $\mathrm{ABX}_{3}$ structure. It has been observed that non-toxic Sn-based halide perovskites are less stable than Pb-based perovskites and degrade very rapidly when exposed to air, mainly because of the +2 oxidation state of $\mathrm{Sn}$ [22]. The Ge-based lead-free perovskites possess low photovoltaic performance because of the 
reduced absorption of light, reduced dielectric constant, and low optical conductivity [23]. Other divalent elements in the periodic table have also been tried as a replacement for lead in the $\mathrm{ABX}_{3}$, but these materials also possess reduced optoelectronic properties due to a high value of bandgap, large carrier effective masses, and low absorption [24,25].

Recently, it has been proposed that two divalent lead ions may be substituted by combining one monovalent ion and one trivalent metal ion, or one tetravalent metal ion, to yield the same overall charge balance as the conventional $\mathrm{APbX}_{3}$ perovskites. This new substitution strategy results in halide double perovskites with the general formula $\mathrm{A}_{2} \mathrm{~B}^{\prime} \mathrm{B}^{\prime \prime} \mathrm{X}_{6}$ and vacancy-ordered halide double perovskites with the general formula $\mathrm{A}_{2} \mathrm{BX}_{6}$, as shown in Figure 1. Similarly, three divalent lead ions can be substituted by two trivalent metal ions, forming another derivative perovskite structure with the general formula $\mathrm{A}_{3} \mathrm{~B}_{2} \mathrm{X}_{9}$. Among these, $\mathrm{A}_{2} \mathrm{~B}^{\prime} \mathrm{B}^{\prime \prime} \mathrm{X}_{6}$ halide double perovskites are deemed to be $\mathrm{a}$ potential alternative to lead halide perovskites as they possess good stability under ambient conditions and excellent optoelectronic properties. The past several years has witnessed a rapid development in the synthesis, study of properties, and optoelectronic applications of a variety of halide double perovskites with the formula $\mathrm{A}_{2} \mathrm{~B}^{\prime} \mathrm{B}^{\prime \prime} \mathrm{X}_{6}$. Although a general overview of double perovskites has been highlighted in some previous reviews [2,26-31], a specific review on recent advancements in $\mathrm{A}_{2} \mathrm{~B}^{\prime} \mathrm{B}^{\prime \prime} \mathrm{X}_{6}$ halide double perovskites has not yet been published. This review summarizes recent advances in searching for new halide double perovskites. Essential results of representative 3D, 2D, and nanocrystal halide double perovskites are highlighted.

\section{Structural Insight Into Halide Double Perovskites}

Halide double perovskites are an important derivative of the conventional halide single perovskite. Metal halide single perovskites have the general formula $\mathrm{ABX}_{3}$ and generally crystallize out in solution with a cubic system which has a $P m \overline{3} m \operatorname{Pm} \overline{3} m$ space group. The metal (B) and halide group (X) form a continuous $\mathrm{BX}_{6}$ octahedra connected by shared corners and the cation (A) occupies the vacant cubo-octahedral interstices. The halide double perovskites have the general formula $\mathrm{A}_{2} \mathrm{~B}^{\prime} \mathrm{B}^{\prime \prime} \mathrm{X}_{6}$, where A represents the cation, as in $\mathrm{ABX}_{3}$, but is mostly $\mathrm{Cs}^{+}$, contrary to $\mathrm{ABX}_{3}$, which generally has a cation of a hybrid nature. The $\mathrm{B}^{\prime}$ and $\mathrm{B}^{\prime \prime}$ represent monovalent and trivalent metals, respectively, and $\mathrm{X}$ is any halogen atom. $\mathrm{A}_{2} \mathrm{~B}^{\prime} \mathrm{B}^{\prime \prime} \mathrm{X}_{6}$ perovskites generally crystallize in a cubic geometry with an $F m \overline{3} m F m \overline{3} m$ space group. In the crystal lattice the octahedra $\mathrm{B}^{\prime} \mathrm{X}_{6}$ and $\mathrm{B}^{\prime \prime} \mathrm{X}_{6}$ are aligned along each other with shared corners, as shown in Figure 1. 

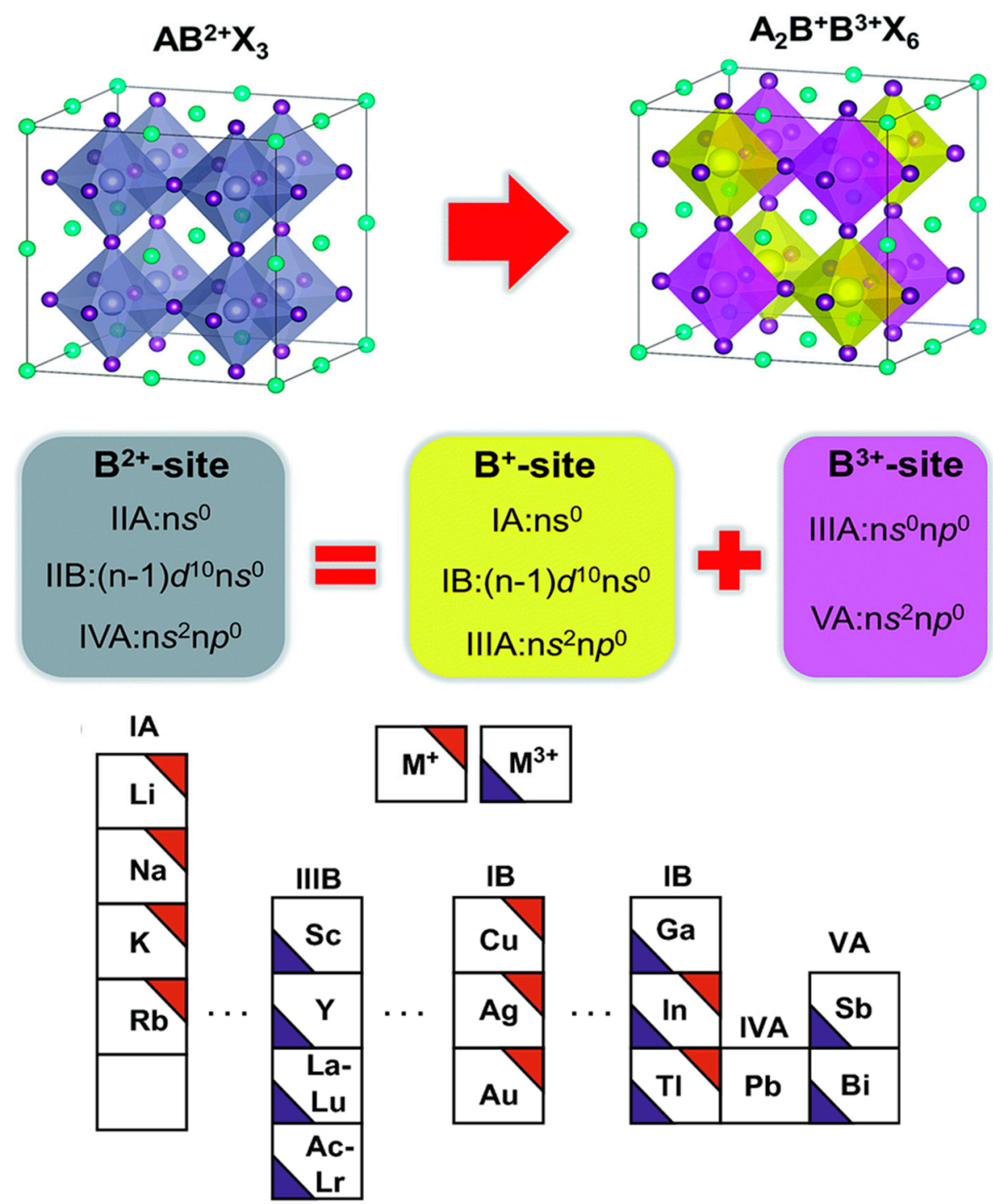

Figure 1. Pb-based perovskites toward $\mathrm{Pb}$-free halide double perovskites. Reproduced with permission from $[26,32]$.

The 3D structure of perovskites is determined by several factors, including ionic radius, the valency of ions, and the coordination type of $\mathrm{A}, \mathrm{B}$, and $\mathrm{X}$ ions. To maintain a stable $3 \mathrm{D}$ perovskite structure, the ionic radii of $\mathrm{A}, \mathrm{B}$, and $\mathrm{X}$ ions, i.e. $\mathrm{RA}, \mathrm{RB}$, and $\mathrm{RX}$, should meet the requirement of Goldschmidt's tolerance factor ( $t$ ) [33] and octahedral factor (O.F.). $t$ is calculated using the formula

$$
t=\frac{\left(R_{A}+R_{B}\right)}{\left[\sqrt{2}\left(R_{B}+R_{X}\right)\right]}
$$

For a halide double perovskite with the general formula $A_{2} B^{\prime} B^{\prime \prime} X_{6}, R B$ is calculated using the formula

$$
R_{B}=\frac{R_{B^{\prime}}+R_{B^{\prime \prime}}}{2}
$$

The O.F. for predicting the structure parameters is calculated by the formula

$$
\text { O.F. }=\frac{R_{B}}{R_{X}}
$$


In order to attain the 3D structure of perovskites, the range for $t$ should be 0.813 to 1.107 and the range for O.F. should be 0.44 to 0.90 [34]. The $t$ value can also predict the extent of symmetry. If the $t$ value approaches or is closer to 1 , then the structure is expected to have high symmetry. To obtain highly symmetrical structures, A, B, and X ions with more suitable radii can be selected, or, firstly, we can select $B$ and $X$, and then we can select an $A$ ion with an $R A$ value such that a $t$ value equal to 1 or close to 1 is obtained [35].

Additionally, a fitness factor $(\Phi)$ is used to distinguish different crystal systems of double perovskites [36]. $\Phi$ can be calculated using the formula

$$
\Phi=\sqrt{2} \frac{R_{A}}{R_{B}+R_{X}}
$$

A cubic crystal system occurs at a fitness of $\Phi>1$ while a tetragonal system occurs at $0.93<\Phi<1$; $0.90<\Phi<0.93$ indicates an orthorhombic system and $\Phi<0.90$ indicates a monoclinic system.

Currently, the most popular approach is to replace two $\mathrm{Pb}^{2+}$ cations with $\mathrm{B}^{+}$and $\mathrm{B}^{3+}$ metal cations or with a $\mathrm{B}^{4+}$ metal cation to yield the double perovskites $\mathrm{A}_{2} \mathrm{~B}^{\prime} \mathrm{B}^{\prime \prime} \mathrm{X}_{6}$ and $\mathrm{A}_{2} \mathrm{~B}(\mathrm{IV}) \mathrm{X}_{6}$, respectively [21,37]. The successful heterovalent replacement of $\mathrm{Pb}$ in double perovskites has explosively attracted research intentions and this field has been extensively studied in recent years. Compared with traditional $\mathrm{APbX}_{3}$ single perovskites, $\mathrm{A}_{2} \mathrm{~B}^{\prime} \mathrm{B}^{\prime \prime} \mathrm{X}_{6}$ halide double perovskites offer long-term stability, environment friendliness, and good optoelectronic properties, structure, and bandgap tunability [19,38-42]. Single crystal perovskites are preferred for device applications because they offer no grain boundaries, domains of continuous crystalline nature, and low trap density. In the following sections, recent advances in single crystal growth, exploration of properties and application of $3 \mathrm{D}$ and $2 \mathrm{D} \mathrm{A}_{2} \mathrm{~B}^{\prime} \mathrm{B}^{\prime \prime} \mathrm{X}_{6}$ halide double perovskites are introduced. In addition, nanocrystals of $\mathrm{A}_{2} \mathrm{~B}^{\prime} \mathrm{B}^{\prime \prime} \mathrm{X}_{6}$ halide double perovskites are observed to show unique properties compared with their bulk counterparts. Recent progress on the synthesis and applications of $\mathrm{A}_{2} \mathrm{~B}^{\prime} \mathrm{B}^{\prime \prime} \mathrm{X}_{6}$ nanocrystals is also highlighted.

\section{3D Halide Double Perovskites}

\section{1. $\mathrm{Cs}_{2} \mathrm{NaBiCl}_{6}$}

This type of $\mathrm{A}_{2} \mathrm{~B}^{\prime} \mathrm{B}^{\prime \prime} \mathrm{X}_{6}$ structure has been known of since 1968, when $\mathrm{Cs}_{2} \mathrm{NaAmCl}_{6}$ was first reported [43]. However, there had been no such term as "double perovskite" at that time. Hence, early research on $\mathrm{A}_{2} \mathrm{~B}^{\prime} \mathrm{B}^{\prime \prime} \mathrm{X}_{6}$ compounds mainly focused on structural investigation, and the optoelectronic properties of $\mathrm{A}_{2} \mathrm{~B}^{\prime} \mathrm{B}^{\prime \prime} \mathrm{X}_{6}$ compounds were seldom noticed. $\mathrm{Cs}_{2} \mathrm{NaBiCl}_{6}$ was first prepared in 1970 through dissolving precursors in concentrated $2 \mathrm{M} \mathrm{HCl}$ and subsequent evaporating the solvent [44]. A single crystal $\sim 1 \mathrm{~cm}$ in length was grown using the melt growth method. Subsequently, a series of $\mathrm{Cs}_{2} \mathrm{NaB}^{\prime \prime} \mathrm{Cl}_{6}$ compounds were also synthesized. B" represents a trivalent metal, which could be $\mathrm{Fe}, \mathrm{Bi}, \mathrm{Tl}, \mathrm{Ti}$, In, Sc, or a lanthanide, etc. In 1972 , the crystal structure of $\mathrm{Cs}_{2} \mathrm{NaBiCl}_{6}$ was found to be cubic and to have an $F m \overline{3} m$ space group [45]. In 1978, Pelle et al. first studied the optical properties of $\mathrm{Cs}_{2} \mathrm{NaBiCl}_{6}$ [46]. The intense absorption peaks were observed at 323 and $350 \mathrm{~nm}$ and low intense peaks were observed at around $375 \mathrm{~nm}$ and $200-260 \mathrm{~nm}$ (four shoulders) at a temperature of $7 \mathrm{~K}$. Increasing the temperature split the $323 \mathrm{~nm}$ peak into two further peaks at $315 \mathrm{~nm}$ and $327 \mathrm{~nm}$. The peak at $375 \mathrm{~nm}$ remained intact with increasing temperature and the $260 \mathrm{~nm}$ shoulder became more intense with an initial temperature increase and then remained intact at higher temperatures. Steady state and pulsed fluorescence spectra results depicted that at excitation wavelengths 253,337 , and $375 \mathrm{~nm}$, emission peaks at 620,720 , and $\sim 720 \mathrm{~nm}$, respectively, were observed at lower temperatures, which altered with a change in temperature. It was also found that $\mathrm{Cs}_{2} \mathrm{NaBiCl}_{6}$ distorts the crystalline phase from cubic at room temperature to tetragonal below $90 \mathrm{~K}$ [47]. $\mathrm{Cs}_{2} \mathrm{NaBiCl}_{6}$ doped with $\mathrm{Mn}^{2+}$ was reported recently which increased its photoluminescence (PL). PL increased from weak emission in the undoped product to an intense PL peak in the orange-red region of the visible spectrum for the doped product [48]. It was synthesized using a hydrothermal approach by dissolving the precursors in $\mathrm{HCl}$ and heating to $80^{\circ} \mathrm{C}$. 
The freshly obtained product was ground and calcined to $210{ }^{\circ} \mathrm{C}$ for $10 \mathrm{~h}$ to increase the homogeneous incorporation of $\mathrm{Mn}^{2+}$. The oxidation state of doped $\mathrm{Mn}^{2+}$ was confirmed by electron paramagnetic resonance (EPR) spectra. $\mathrm{Mn}^{2+}$ doping decreased the thermal stability of this double perovskite irrespective of its concentration. It was speculated that the $\mathrm{Cs}_{2} \mathrm{NaBiCl}_{6}$ absorbance phenomenon could be explained by taking as an example the absorption behavior of $\mathrm{Bi}^{3+}$-doped $\mathrm{Cs}_{2} \mathrm{SnCl}_{6}$, which depicted a strong blue luminescent peak at $455 \mathrm{~nm}$ with a photoluminescence quantum yield (PLQY) which reached $80 \%$ [42].

\section{2. $\mathrm{Cs}_{2} \mathrm{AgBiX}(\mathrm{X}=\mathrm{Cl}, \mathrm{Br})$}

The optoelectronic properties of $\mathrm{Cs}_{2} \mathrm{~B}^{\prime} \mathrm{B}^{\prime \prime} \mathrm{X}_{6}$ were known in early studies when $\mathrm{A}_{2} \mathrm{~B}^{\prime} \mathrm{B}^{\prime \prime} \mathrm{X}_{6}$ structured compounds were explored. Over the past several years, the need for toxicity-free and stable lead-free alternative perovskites has directed researchers' efforts to relate structural and photoresponsive features of these double perovskites with those of lead-based halide perovskites. Among these, $\mathrm{Cs}_{2} \mathrm{AgBiBr}_{6}$ has been extensively explored. $\mathrm{Cs}_{2} \mathrm{AgBiBr}_{6}$ together with $\mathrm{Cs}_{2} \mathrm{AgBiCl}_{6}$ were reported in 2016 to have bandgaps of $2.19 \mathrm{eV}$ and $2.77 \mathrm{eV}$, respectively (Figure 2) [20]. These two double perovskites exist in a cubic crystal system with $F m \overline{3} m$ space groups. These double perovskites are able to be synthesized with two different methods, i.e., the hydrothermal method and solid-state method. Initially, these perovskites were found to be stable in air, but it was found that $\mathrm{Cs}_{2} \mathrm{AgBiBr}_{6}$ was only stable for a few weeks [20]. Later on, $\mathrm{Cs}_{2} \mathrm{AgBiBr}_{6}$ crystal size and quality were improved. A single crystal $4 \mathrm{~mm}$ in size was grown by Slavney et al., as shown in Figure 3 [49]. Similarly, a $\mathrm{Cs}_{2} \mathrm{AgBiBr}_{6}$ single crystal $\sim 4 \mathrm{~mm}$ in size was also grown using a solution cooling method in 2017, which was mistakenly mentioned as inverse temperature crystallization [50].
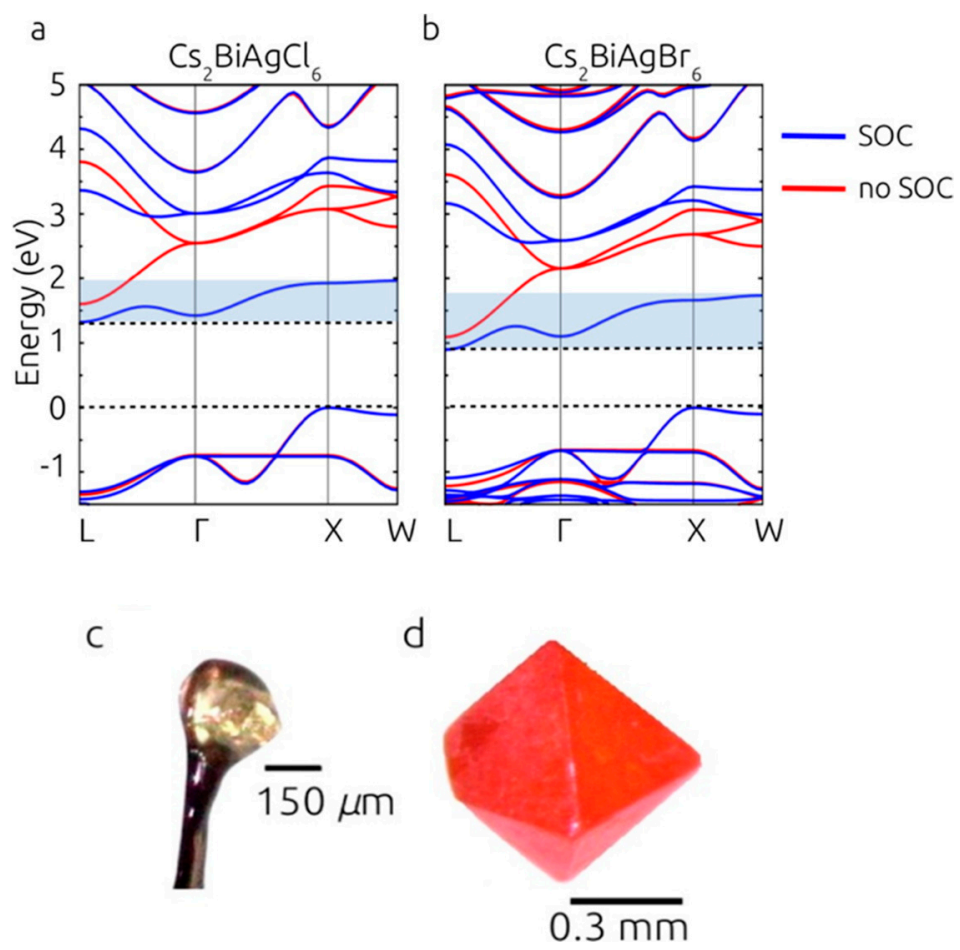

Figure 2. Band structures of $\mathrm{Cs}_{2} \mathrm{BiAgCl}_{6}(\mathbf{a})$ and $\mathrm{Cs}_{2} \mathrm{BiAgBr}_{6}(\mathbf{b})$. The calculations were performed with (blue lines) and without (red lines) spin-orbit coupling. The light blue shading highlights the width of the lowest conduction band: $0.6 \mathrm{eV}$ for $\mathrm{Cs}_{2} \mathrm{BiAgCl}_{6}$ and $0.9 \mathrm{eV}$ for $\mathrm{Cs}_{2} \mathrm{BiAgBr}_{6}$. Single crystals of $\mathrm{Cs}_{2} \mathrm{BiAgCl}_{6}$ (c) and $\mathrm{Cs}_{2} \mathrm{BiAgBr}_{6}$ (d). Reproduced with permission from [20]. 


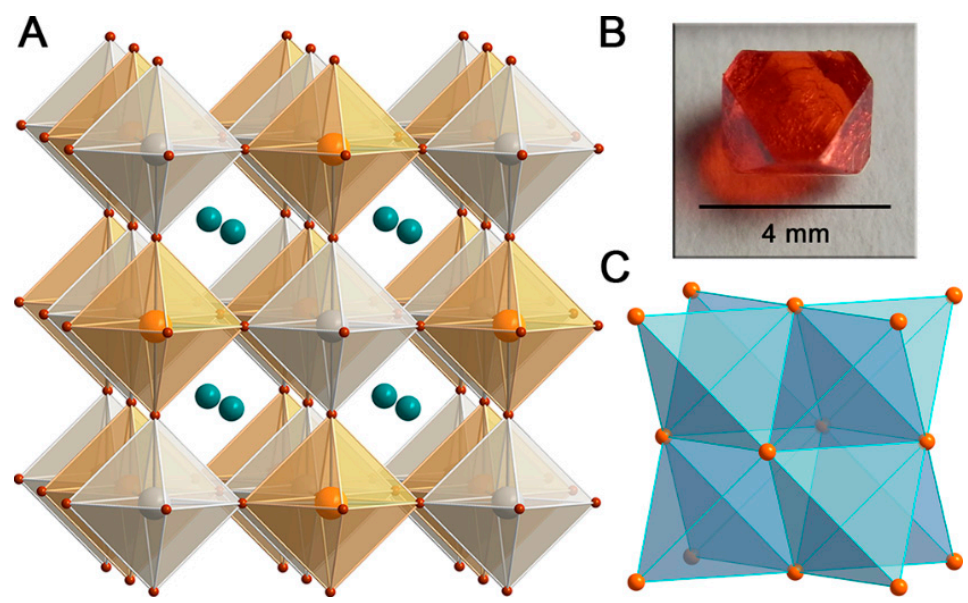

Figure 3. (a) Crystal structure of $\mathrm{Cs}_{2} \mathrm{AgBiBr}_{6}$. Orange, gray, turquoise, and brown spheres represent $\mathrm{Bi}$, $\mathrm{Ag}, \mathrm{Cs}$, and $\mathrm{Br}$ atoms, respectively. (b) Photograph of a $\mathrm{Cs}_{2} \mathrm{AgBiBr}_{6}$ single crystal. (c) The edge-sharing tetrahedra of $\mathrm{B} \mathrm{Bi}^{3+}$ face-centered-cubic sublattice. Reproduced with permission from [49].

Theoretical investigation of $\mathrm{Cs}_{2} \mathrm{AgBiBr}_{6}$ was carried out further by Savory et al. in their attempt to explore the suitability of double perovskites for photovoltaic applications. They investigated the electronic structure and stability of this kind of compound and assessed it as a lead alternative for optoelectronic application using density functional theory within periodic boundary conditions through the Vienna Ab Initio Simulation Package and Generalized Gradient Approximation approach [51]. They revealed that the Ag d orbital and Bi s orbital are mismatched fundamentally, which results in an indirect large bandgap because of a reduction in the conduction bandwidth. If the Ag is replaced by other metals with ns2 orbitals like $\mathrm{Tl}^{+}$, then the s-s interactions of cations can result in a direct bandgap. The spectroscopic limited maximum efficiencies of the Ag- and Bi-based double perovskites are low due to a large indirect bandgap. Thermodynamic stability of Ag- and Bi-based double perovskites is also an issue, and only chlorides and bromides are stable out of the majority. It is favorable to synthesize double perovskites with matching ns2 in cations to achieve similar properties to $\mathrm{MAPbI}_{3}$ perovskite [51]. Theoretical calculations showed that the valence band could be adjusted to an indirect band by Ag $4 \mathrm{~d}$ orbitals and halide $3 \mathrm{p} / 4 \mathrm{p}$ orbitals [21]. In another attempt, Xiao et al. studied theoretically the thermodynamic stability and the defect chemistry of $\mathrm{Cs}_{2} \mathrm{AgBiBr}_{6}$. They revealed that the deep acceptors, $\mathrm{Bi}$ vacancies and $\mathrm{AgBi}$, are the main points of deep defects under $\mathrm{Br}$-rich conditions. The coupling of the $6 \mathrm{~s}$ of $\mathrm{Bi}$ and the $6 \mathrm{p}$ of Br orbitals is not as strong as in Pb-based perovskites, and it contributes less to the valence band maximum (VBM) in double perovskites. The VBM is constituted by $\mathrm{Ag} 4 \mathrm{~d}$ and B 4p orbitals. Thus, the Ag vacancy is easily formed and can act as a shallow acceptor [52]. It was predicted that for crystal growth bromine-poor and bismuth-rich environments in a solvent were most suitable to decrease deep defect formation and to improve photovoltaic applications.

Schade et al. studied temperature-dependent crystalline phase transitions in $\mathrm{Cs}_{2} \mathrm{AgBiBr}_{6}$. They synthesized a single $\mathrm{Cs}_{2} \mathrm{AgBiBr}_{6}$ crystal of about $1 \mathrm{~mm}$ in size through the hydrothermal method in DMSO, and then used $\mathrm{HBr}$ for large single crystal growth. The crystalline phase changed from a low temperature tetragonal phase to a high temperature cubic phase at $\sim 122 \mathrm{~K}$. The photophysical properties of $\mathrm{Cs}_{2} \mathrm{AgBiBr}_{6}$ were correlated with the tetragonal and cubic phases. The PL peak was observed at $\sim 1.97 \mathrm{eV}$ at $25 \mathrm{~K}$ and a $398 \mathrm{~nm}$ excitation wavelength with a full width at half maximum of $\sim 0.2 \mathrm{eV}$. Upon increasing the temperature, the width of the PL peak increased to $\sim 0.9 \mathrm{eV}$ with a very small shift in peak position. The indirect bandgap values varied from $1.83 \mathrm{eV}$ to $\sim 1.97 \mathrm{eV}$ at room temperature and $25 \mathrm{~K}$, respectively. This change in bandgap with temperature is a phenomenon which is contrary to lead-based halide perovskites [53]. Lan et al. studied halide migration in $\mathrm{Cs}_{2} \mathrm{AgBiX}_{6}$ [54]. It was found that the vacancy formation energy and migration barrier for $\mathrm{Br}$ are lower than for $\mathrm{Cl}$. Hence, $\mathrm{Br}$ ion migration is higher in $\mathrm{Cs}_{2} \mathrm{AgBiBr}_{6}$. 
In addition to these studies on $\mathrm{Cs}_{2} \mathrm{AgBiBr}_{6}$, Steele et al. studied the charge carrier and conduction band properties of $\mathrm{Cs}_{2} \mathrm{AgBiBr}_{6}$ by using instrumental techniques (single crystal XRD, optical excitation and temperature-dependent emission spectroscopy, and Raman scattering) and a theoretical approach. The deep conduction band energy levels were identified and the Fröhlich coupling constant was found to be around $230 \mathrm{meV}$ from the temperature-dependent PL emission linewidth analysis, a value which was much higher than that of lead halide perovskites (40 to $60 \mathrm{meV}$ ). Fine XRD analysis showed that an $\mathrm{AgBr}_{6}{ }^{5-}$ type of octahedral dominated the internal bonding and Raman spectrum revealed that these $\mathrm{AgBr}_{6}{ }^{5-}$ octahedra vibrate and dominate in lattice dynamics. It was depicted by excitation spectroscopy that metal orbital-induced energy levels are present in the region above the conduction band (CB). Quasi-resonant Raman studies confirmed these levels and depicted longitudinal optical multiphonon combinations up to the fourth order. The bandgap calculated from diffuse reflectance spectroscopy data using the Kubelka Munk function $\mathrm{F}(\mathrm{R})$ was $2.25 \mathrm{eV}$ (indirect) and 2.41 (direct) [55].

Experimental calculations of the bandgap of double perovskites from optical data predict that double perovskites have a variable bandgap. Theoretical studies of bandgap structures also reveal this feature. However, most electronic transitions in double perovskites lead to an indirect bandgap, as shown in Figure 4. The bandgap of double perovskites can be selectively varied from direct to indirect by tuning the conduction band and retaining the valence band. The double perovskite structure with the general formula $\mathrm{A}_{2} \mathrm{BB}^{\prime} \mathrm{X}_{6}$ can be tuned by selecting a d10 B metal for the valence band states. For conduction band construction, an $\mathrm{s} / \mathrm{p}$ orbital can be provided by the $\mathrm{B}^{\prime}$ metal. The conduction band can be lowered by tuning $\mathrm{B}^{\prime}$ with $\mathrm{s} 0$ to $\mathrm{s} 2$.

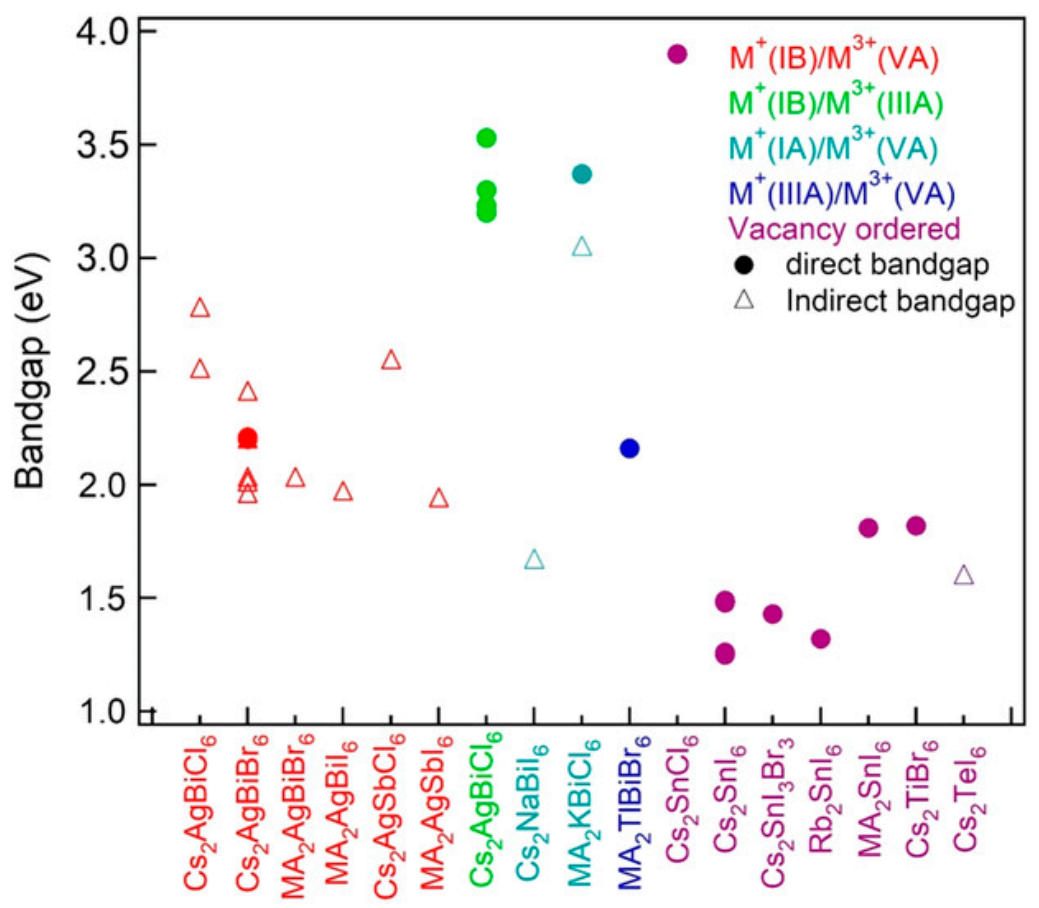

Figure 4. Bandgap values of some lead-free double perovskites. Reproduced with permission from [56].

Du et al. engineered compositional changes at the $\mathrm{B}$ site in $\mathrm{ABX}_{3}$ perovskites by incorporating AgIBiIII and AgISbIII [39]. This opened up a new dimension in synthesizing new perovskites as an alternative to toxic lead perovskites. Powder XRD peaks shifted in the heterovalent substituted perovskite structures because of the synergistic effect between the $\mathrm{Ag}$ and $\mathrm{Bi}$ (or $\mathrm{Sb}$ ). Density functional theory has also supported the blue shift in the photoluminescence. The new product was found to have a direct bandgap. Furthermore, the bandgap was reduced due to heterovalent substitution. It was also stated that the ordering in the double perovskite lattice affects the band structure. The ordered system 
may result in an indirect bandgap, and a pseudo-direct bandgap shows a randomly ordered system. A narrow bandgap arises from an ordered system with less Bi-on-Ag or less Ag-on-Bi [39].

$\mathrm{Cs}_{2} \mathrm{AgBiBr}_{6}$ is comparatively more stable than other halide perovskites but it is a material of an indirect bandgap. Hence, the other aim is to alter its bandgap transition to a direct bandgap transition by substitution of monovalent or trivalent metals or synthesizing other similar structured materials. The $\mathrm{Bi}^{3+}$ in $\mathrm{Cs}_{2} \mathrm{AgBiBr}_{6}$ offers a wide range of substitutions to trivalent metals to engineer the bandgap of double perovskites (Figure 5) [57]. Du et al. alloyed trivalent metals (In and Sb) in $\mathrm{Cs}_{2} \mathrm{AgBiBr}_{6}$ in 2017 [58]. The new combinations $\mathrm{Cs}_{2} \mathrm{AgBi}_{1-\mathrm{x}} \mathrm{M}_{\mathrm{x}} \mathrm{Br}_{6}(\mathrm{M}=\mathrm{Sb}, \mathrm{In})$ could retain the parent crystalline phase by accommodating up to $75 \%$ InIII and 37.5\% SbIII. With an increase in substitution the lattice parameters altered because of the difference in the atomic radii of BiIII (117 pm), InIII (94 pm), and SbIII (90 pm) according to Vegard's law [59]. Alloying of above 75\% InIII and 37.5\% SbIII led to instability in the structure. Density functional theory calculations suggested that $\mathrm{Sb}$ and In alloying introduced different orbitals in the valence and conduction bands. Because of different electronic configurations, InIII alloying increased the bandgap (2.12 eV to $2.27 \mathrm{eV}$ ) and SbIII alloying decreased the bandgap $(2.12 \mathrm{eV}$ to $1.86 \mathrm{eV})$. However, the bandgap remained indirect. Nevertheless, it opened up a wide range of substitution of $\mathrm{Bi}^{3+}$ and also showed the complexity and unique behavior of each different metal [58]. The reduction in the bandgap of $\mathrm{Cs}_{2} \mathrm{AgBiBr}_{6}$ by pnictogen alloying was also studied using another effort. $\mathrm{Sb}$ alloying in $\mathrm{Cs}_{2} \mathrm{AgBiBr}_{6}$ reduced the bandgap, and the alloyed mixed halide double perovskite, $\mathrm{Cs}_{2} \mathrm{AgBi}_{1-\mathrm{x}} \mathrm{Sb}_{\mathrm{x}} \mathrm{Br}_{6}$ showed a $1.6 \mathrm{eV}$ bandgap [57]. Thallium was also alloyed in $\mathrm{Cs}_{2} \mathrm{AgBiBr}_{6}$ double perovskite. Tl alloying reduced the bandgap to the range of photovoltaic absorbers. It was the first lead-free double perovskite that had a bandgap energy and carrier lifetime in line with that of $\mathrm{MAPbI}_{3}$. The $\mathrm{Cs}_{2} \mathrm{AgBiBr}_{6}$ orange truncated octahedral product changed to an opaque black octahedral product upon $\mathrm{TlBr}$ addition in the solution. The resulting compound $\mathrm{Cs}_{2}\left(\mathrm{Ag}_{1-\mathrm{a}} \mathrm{Bi}_{1-\mathrm{b}}\right) \mathrm{Tl}_{\mathrm{x}} \mathrm{Br}_{6}$ $(0.003<\mathrm{x}=\mathrm{a}+\mathrm{b}<0.075)$ contained $\mathrm{Tl}$ atomic content ranging $0.03-0.075 \%$ and showed an almost similar bandgap energy and carrier lifetime to that of $\mathrm{MAPbI}_{3}$. The bandgap of $\mathrm{Cs}_{2} \mathrm{AgBiBr}_{6}(1.95 \mathrm{eV})$ was reduced by $0.5 \mathrm{eV}$ by $\mathrm{Tl}$ alloying. It has been observed that at higher $\mathrm{Tl}$ concentration, the preferred alloying occurs by substituting the Ag, and dilute alloying prefers the substitution of Bi by Tl. The larger lattice of a double perovskite can accommodate $\mathrm{Tl}^{+}$alloying, and the smaller lattice of a perovskite structure prefers a $\mathrm{Tl}^{3+}$ substitution where atmospheric oxygen plays a role in oxidizing $\mathrm{Tl}^{+}$ to $\mathrm{Tl}^{3}+$. X-ray photoelectron spectroscopy studies have confirmed the uniform distribution of $\mathrm{Tl}$ in the perovskite structure. $\mathrm{Tl}$ doping results in substitution of $\mathrm{Ag}^{+}$ions by $\mathrm{Tl}^{+}$at the concentrated $\mathrm{Tl}$ level and forms $(\mathrm{MA})_{2}\left(\mathrm{Tl}_{1-\mathrm{a}} \mathrm{Bi}_{1-\mathrm{b}}\right) \mathrm{Ag}_{\mathrm{x}} \mathrm{Br}_{6}$. Substitution of $\mathrm{Bi}^{3+}$ by $\mathrm{Tl}^{3+}$ in a lower concentration of $\mathrm{Tl}$ forms $\mathrm{Cs}_{2}\left(\mathrm{Ag}_{1-\mathrm{a}} \mathrm{Bi}_{1-\mathrm{b}}\right) \mathrm{Tl}_{\mathrm{x}} \mathrm{Br}_{6}$. This opens up the possibility of further incorporation of metals within lead-free double perovskites to reduce the bandgap and for direct bandgap transitions [60].

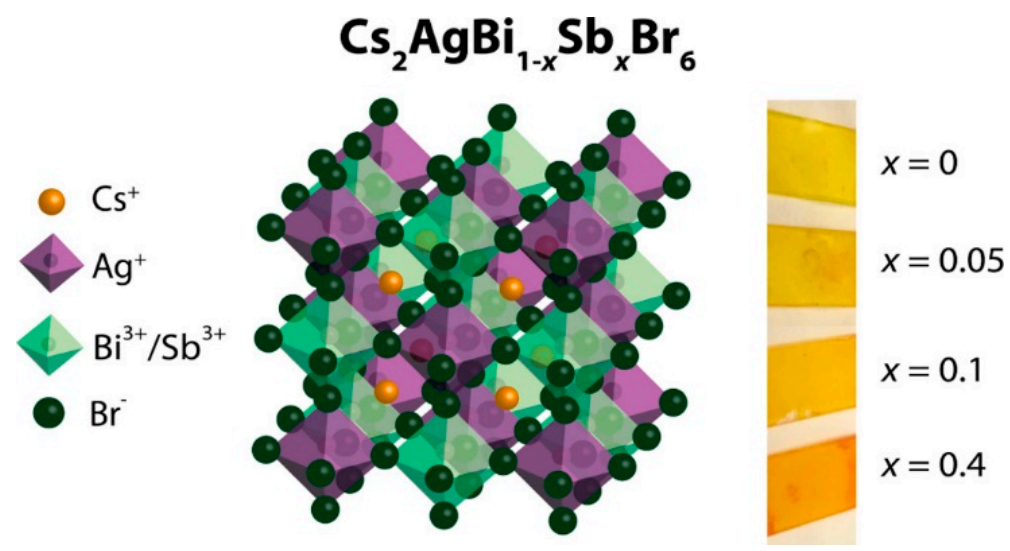

Figure 5. Crystal structure and photos of $\mathrm{Cs}_{2} \mathrm{AgBi}_{1-x} \mathrm{Sb}_{\mathrm{x}} \mathrm{Br}_{6}$. Reproduced with permission from [57]. 
$\mathrm{Cs}_{2} \mathrm{AgBiCl}_{6}$ double perovskite was explored by a combined synthetic and theoretical approach [61]. Firstly, by using first principles calculations a tunable bandgap and low carrier effective masses, which are a sign of good optoelectronic properties, were predicted. $\mathrm{Cs}_{2} \mathrm{AgBiCl}_{6}$ single phase product was synthesized using a solid-state approach. The crystal has an $F m \overline{3} m$ space group with a face-centered cubic structure which has alternating $\mathrm{AgCl}_{6}$ and $\mathrm{BiCl}_{6}$ octahedra. Similarly to the extensively studied $\mathrm{Cs}_{2} \mathrm{AgBiCl}_{6}$, this double perovskite was found to possess an indirect bandgap of $2.2 \mathrm{eV}$. It also possessed good stability for weeks and had a persistent bright yellow color, as well as good optical properties [61].

\section{3. $\mathrm{Cs}_{2} \mathrm{AgSbX}_{6}(\mathrm{X}=\mathrm{Cl}, \mathrm{Br})$}

Pnictogens like $\mathrm{Sb}$ have also been incorporated at the $\mathrm{B}^{3+}$ site in halide double perovskites. The double perovskite $\mathrm{Cs}_{2} \mathrm{AgSbBr}_{6}$ was successfully explored using an experimental approach recently (in 2019) [62]. The perovskite phase was formed after prolonged hydrothermal reaction. Small black crystals of $\mathrm{Cs}_{2} \mathrm{AgSbBr}_{6}$ were collected on the surface of large yellow phases and impure phases like $\mathrm{Cs}_{3} \mathrm{Sb}_{2} \mathrm{Br}_{9}$ and $\mathrm{Cs}_{2} \mathrm{SbBr}_{6}$. One-millimeter-sized crystals could be harvested after one month of heating. The black crystals at room temperature turned brown on heating in a vacuum or $\mathrm{N}_{2}$ environment. It was observed that $\mathrm{Sb}^{5+}$ was present in the black-colored compound from the XPS results shown in Figure 6. A sufficient charge transfer between $\mathrm{Sb}^{3+}$ and $\mathrm{Sb}^{5+}$ resulted in a darker color. Theoretical calculations showed that the reduction in the bandgap from $\mathrm{Cs}_{2} \mathrm{AgBiBr}_{6}$ to $\mathrm{Cs}_{2} \mathrm{AgSbBr}_{6}$ was due to the $5 \mathrm{~s} 5 \mathrm{p}$ of $\mathrm{Sb}$, which lowered the conduction band. The crystal structure of the compound showed that it has a cubic system with an $F m \overline{3} m$ space group. A UV-visible absorption base of crystals appeared at $\sim 1.64 \mathrm{eV}$. The solar cell based on $\mathrm{Cs}_{2} \mathrm{AgSbBr}_{6}$ showed an open-circuit voltage of $353.29 \mathrm{mV}$, short-circuit current density of $0.08 \mathrm{~mA} / \mathrm{cm}^{2}$, fill factor of $35.9 \%$, and PCE of $0.01 \%$ [62]. The low efficiency of the device was attributed to the impurity phases present in the product. However, the same device structure with Bi showed an efficiency of $0.06 \%$, which indicated that the device structure was also a factor in low efficiency. Hence, more improvement in film formation and checking the suitability of the interface may improve the solar cell performance. 

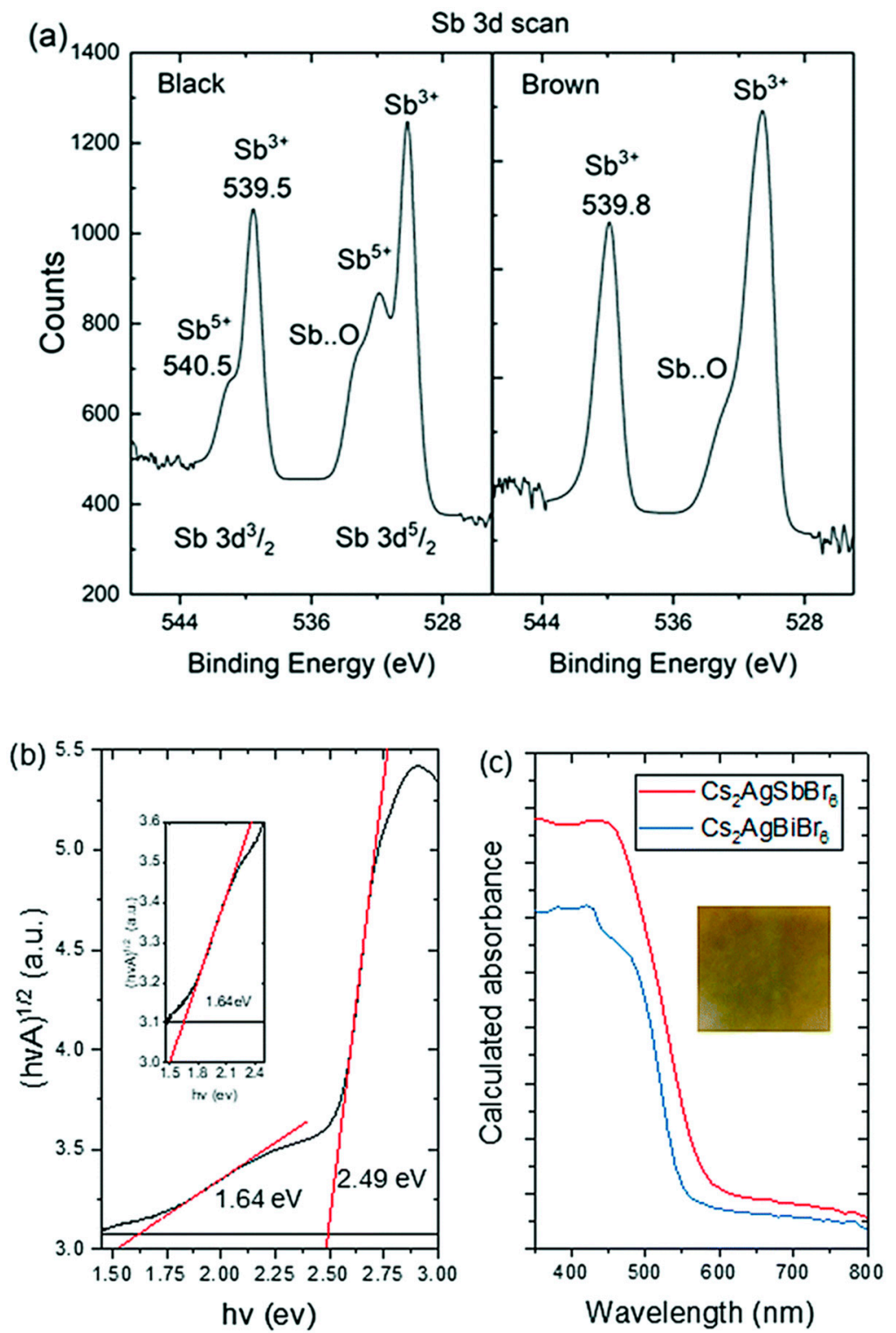

Figure 6. (a) XPS peak of $\mathrm{Sb} 5 \mathrm{~d}$ orbital, (b) Tauc plot of the crystalline product showing the bandgap of $\mathrm{Cs}_{2} \mathrm{AgSbBr}_{6}$, and (c) absorption spectra of $\mathrm{Cs}_{2} \mathrm{AgSbBr}_{6}$ and $\mathrm{Cs}_{2} \mathrm{AgBiBr}_{6}$. Reproduced with permission from [62].

$\mathrm{A} \mathrm{Cl}$ analogue of $\mathrm{Cs}_{2} \mathrm{AgSbBr}_{6}$ was reported by Deng et al. in 2017. They used a hydrothermal approach to synthesize $\mathrm{Cs}_{2} \mathrm{AgSbCl}_{6}$, which was also a double perovskite with an indirect bandgap [63]. This double perovskite showed absorption near the UV region from 200 to $420 \mathrm{~nm}$. The bandgap as calculated from UV-visible data and a Tauc plot was $2.60 \mathrm{eV}$. They also synthesized nanoparticles of $\mathrm{Cs}_{2} \mathrm{AgSbCl}_{6} / \mathrm{TiO}_{2}$. This heterostructure absorbed strongly in the visible region of light and the $\mathrm{TiO}_{2}$ heterojunction increased the separation of carriers generated by light and also enhanced the light absorption ability [63]. Karmakar et al. reported in 2018 a new lead-free copper-doped double perovskite structure with the formula $(\mathrm{Cu}) \mathrm{Cs}_{2} \mathrm{SbAgCl}_{6}$. The bandgap of this new perovskite was considerably decreased by copper doping from an un-doped structure with a bandgap of $2.65 \mathrm{eV}$ to a doped structure with a bandgap of about $1.02 \mathrm{eV}$. The characterization results showed a cubic geometry for $(\mathrm{Cu}) \mathrm{Cs}_{2} \mathrm{SbAgCl}_{6}$. $\mathrm{Cu}^{2+}$ substituted the $\mathrm{Ag}^{+}$ions in the lattice and resulted in multiple defect sites. The low doping concentration of $\mathrm{Cu}^{2+}$ resulted in a localized transition. This perovskite material offers the additional benefit of long-term stability lasting about 365 days [40]. 


\section{4. $\mathrm{Cs}_{2} \mathrm{AgInX}_{6}(\mathrm{X}=\mathrm{Cl}, \mathrm{Br})$}

Trivalent metals of group-IIIA in the periodic table can completely substitute $\mathrm{Bi}^{3+}$ in $\mathrm{Cs}_{2} \mathrm{AgInCl}_{6}$. Indium is a suitable trivalent alternative of Bi because of its electronic configuration. In 2017, Volonakis et al. reported a halide double perovskite with $\mathrm{In}^{3+}$ and $\mathrm{Ag}^{+}$at the $\mathrm{B}$ sites and $\mathrm{Cs}^{+}$at the $\mathrm{A}$ site (Figure 7) [64]. The double perovskite $\mathrm{Cs}_{2} \mathrm{AgInCl}_{6}$ was found to be photosensitive with a bandgap of $3.3 \mathrm{eV}$. XRD data analysis showed that its space group was $F m \overline{3} m$. Photoluminescence was found at around $2.1 \mathrm{eV}$ and reversible color change behavior (white to orange) was also observed under UV light illumination (Figure 7). It was also reported that the optical properties and bandgap could be tuned by synthesizing $\mathrm{Cl}$ or $\mathrm{Br}$ alternatives of $\mathrm{Cs}_{2} \mathrm{AgInX}_{6}$ or by using a mixed halide composition.
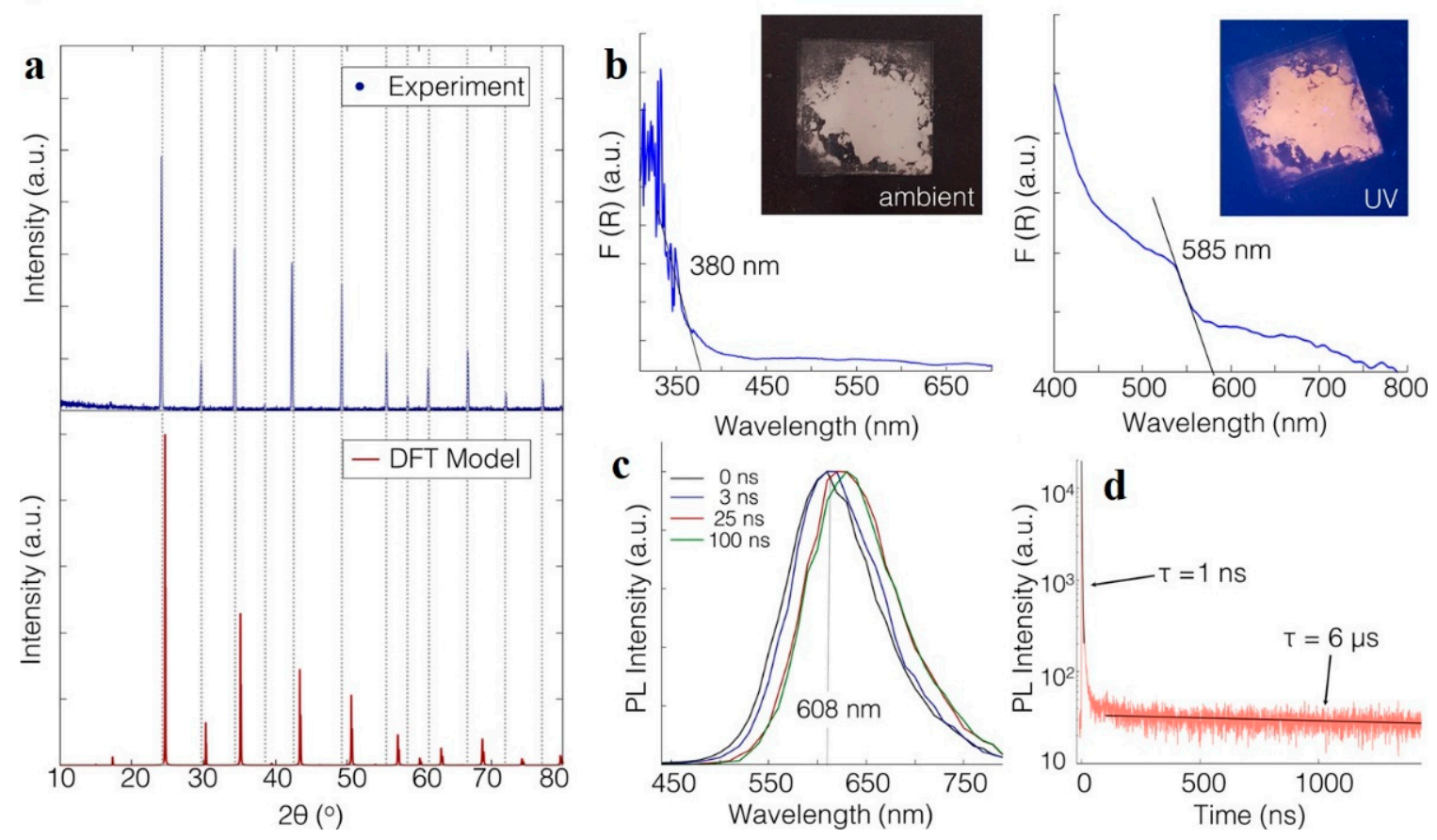

Figure 7. (a-d) Structural and optical characterization of $\mathrm{Cs}_{2} \mathrm{InAgCl}$. Reproduced with permission from [64]. Legend: PL, photoluminescence; DFT: density functional theory.

The synthesis of double perovskites with group-IIIA metal ions further expands the class of lead-free environment-friendly perovskites with potential photovoltaic application. The theoretical prediction of the bandgap of $\mathrm{Cs}_{2} \mathrm{AgIn}_{6}$ by performing first principles calculations concluded that these perovskites would have a direct bandgap. Tran et al. proposed a strategy with which to tune the bandgap from a direct to an indirect nature which involved compositionally engineering the conduction and valence bands [65]. The crystal momentum determination of the conduction band and valence band indicated that in the cubic Brilluoin region, the energy rises in bands derived from the s orbital ( $\Gamma$ to $\mathrm{X})$ and decreases in bands derived from the $\mathrm{p}$ orbital. This crystal momentum of sand porbital-derived bands has already been described in the literature for $\mathrm{MAPbI}_{3}$ by Hutter and co-workers (Figure 8) [66]. 

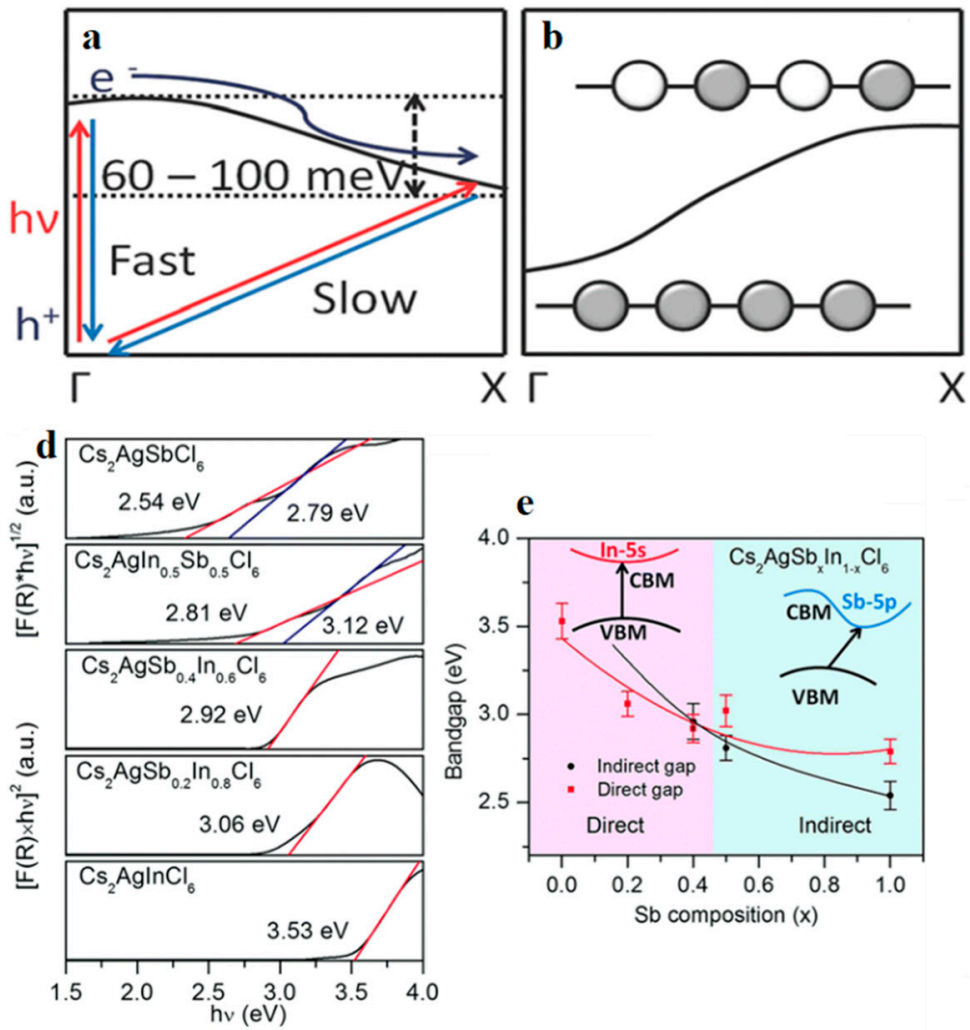

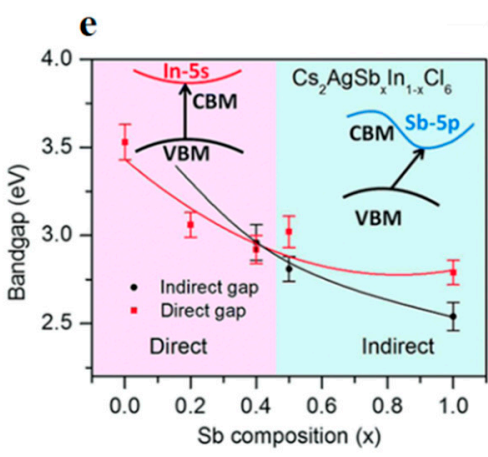

$\mathbf{f}$



g

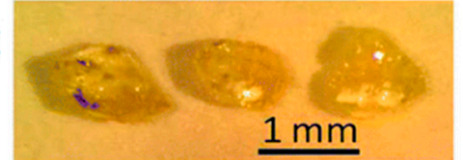

$\mathrm{Cs}_{2} \mathrm{AgInCl}_{6}$

Figure 8. (a) Proposed band diagram for tetragonal $\mathrm{MAPbI}_{3},(\mathbf{b})$ band structure for s-orbital-derived bands, and (c) band structure for p-orbital-derived bands. (d) Tauc plots for $\mathrm{Cs}_{2} \mathrm{AgSbCl}_{6}$, $\mathrm{Cs}_{2} \mathrm{AgSb}_{0.5} \mathrm{In}_{0.5} \mathrm{Cl}_{6}, \mathrm{Cs}_{2} \mathrm{AgSb}_{0.4} \mathrm{In}_{0.6} \mathrm{Cl}_{6}, \mathrm{Cs}_{2} \mathrm{AgSb}_{0.2} \mathrm{In}_{0.8} \mathrm{Cl}_{6}$, and $\mathrm{Cs}_{2} \mathrm{AgInCl}_{6}$. The plots show a transition from an indirect to a direct bandgap. (e) Phase diagram for $\mathrm{Cs}_{2} \mathrm{AgSb}_{\mathrm{x}} \mathrm{Ag}_{1-\mathrm{x}} \mathrm{Cl}_{6}$. Single crystals $(\mathbf{f}, \mathbf{g})$ of double perovskites $\mathrm{Cs}_{2} \mathrm{AgSbCl}_{6}$ and $\mathrm{Cs}_{2} \mathrm{AgInCl}_{6}$. Reproduced with permission from [65].

The value of the $\mathrm{Cs}_{2} \mathrm{AgInCl}_{6}$ bandgap is variable across different literature reports. Zhou et al. found that $\mathrm{Cs}_{2} \mathrm{AgInCl}_{6}$ has a direct bandgap by theoretical calculation $(3.33 \mathrm{eV})$ and by using an experimental approach $(3.23 \mathrm{eV})$ [67]. Crystals 1.5 to $5 \mathrm{~mm}$ in size were grown and the crystal structure of $\mathrm{Cs}_{2} \mathrm{AgInCl}_{6}$ showed that $\left[\mathrm{AgCl}_{6}\right]$ and $\left[\mathrm{InCl}_{6}\right]$ octahedra alternate with each other in the unit cell lattice and that AgIn forms a similar lattice to rock salt $(\mathrm{NaCl})$ (Figure 9). This double perovskite depicted a broad PL peak at $635 \mathrm{~nm}$ upon irradiation with a $370 \mathrm{~nm}$ laser. The crystal was stable and showed the same optical behavior when placed under ambient conditions for 26 days. Thermally, the structure was stable up to $400{ }^{\circ} \mathrm{C}$ and started decomposing at $539{ }^{\circ} \mathrm{C}$ with the expected decomposition product of $\mathrm{CsAgCl}_{2}$ and $\mathrm{CsInCl}_{4}$. 

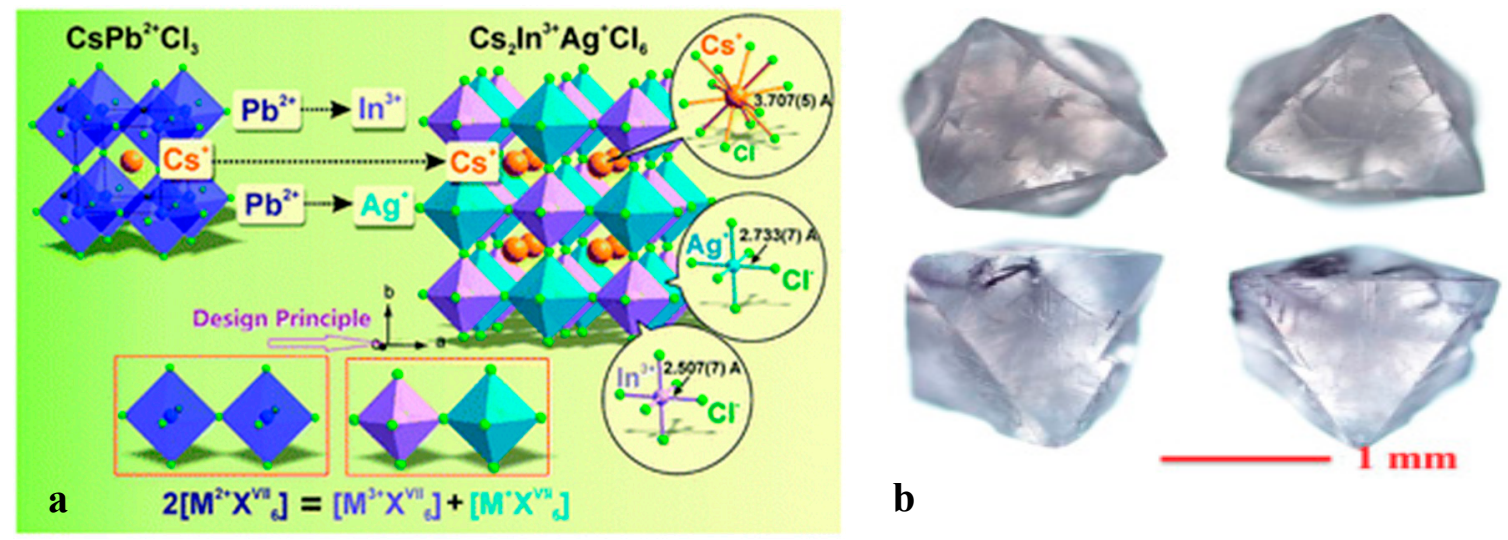

b

Figure 9. (a) Crystal structures of $\mathrm{CsPbCl}_{3}$ and $\mathrm{Cs}_{2} \mathrm{AgInCl}_{6}$, highlighting the $\mathrm{BX}_{6}$ octahedra in these $\mathrm{ABX}_{3}$ perovskite-type compounds; the general design principle of chemical unit substitution is also demonstrated. (b) Optical image of a $\mathrm{Cs}_{2} \mathrm{AgInCl}_{6}$ single crystal. Reproduced with permission from [67].

Later in 2018, Luo et al. systematically studied the crystal growth and structural and optoelectronic properties of $\mathrm{Cs}_{2} \mathrm{AgInCl}_{6}$ [68]. $\mathrm{Cs}_{2} \mathrm{AgInCl}_{6}$ crystals were grown using a combination of a hydrothermal method and a solution temperature lowering method. Small $\mathrm{Cs}_{2} \mathrm{AgInCl}_{6}$ crystals were synthesized using the hydrothermal method at $180^{\circ} \mathrm{C}$. Large, good-quality crystals were grown by lowering the temperature at a rate of $0.5^{\circ} \mathrm{C} /$ hour in a Teflon autoclave. It was observed that nucleation occurs in the solution. A single crystal $2.88 \mathrm{~mm} \times 2.81 \mathrm{~mm} \times 1.95 \mathrm{~mm}$ in size could be harvested. The crystal was of good quality and a low trap state density of $8.6 \times 108 \mathrm{~cm}^{-3}$ was achieved. This trap state density value was comparatively lower than that of a conventional Pb-based perovskite, with $1.8 \times 109 \mathrm{~cm}^{-3}$ observed for a single crystal of $\mathrm{MAPbI}_{3}(\mathrm{Cl})$ [7]. The crystal was stable for more than five months under ambient conditions and could tolerate a temperature of up to $507^{\circ} \mathrm{C}$. In addition, this single crystal was shown to have a concentration-dependent trap state density. Crystals obtained from 0.067 molar and 0.05 molar solutions showed trap state densities of $8.6 \times 108 \mathrm{~cm}^{-3}$ and $7.3 \times 109 \mathrm{~cm}^{-3}$, and carrier mobilities of $3.31 \mathrm{~cm}^{2} \mathrm{~V}^{-1} \mathrm{~s}^{-1}$ and $2.29 \mathrm{~cm}^{2} \mathrm{~V}^{-1} \mathrm{~s}^{-1}$, respectively. The single crystal showed different resistances in a vacuum $(5.7 \times 1011 \Omega)$ and air $(2.7 \times 1010 \Omega)$, which might be because of conductance caused by surface oxygen. Parity-forbidden transitions were observed from the conduction band minimum to the valence band maximum. The PL emission peak was obtained at $595 \mathrm{~nm}$ when the laser beam was focused on the crystal surface. When a laser with a power of $\sim 25 \mathrm{~mJ} \mathrm{~cm}^{-2}$ penetrated inside the crystal, two PL peaks were observed, with the stronger at $595 \mathrm{~nm}$ and the weaker at $425 \mathrm{~nm}$. The single crystal showed a comparatively long PL lifetime at $595 \mathrm{~nm}$. The UV detector based on $\mathrm{Cs}_{2} \mathrm{AgInCl}_{6}$ showed comparative device properties to those of already-reported UV detectors [69]. Dark current, detectivity, response time, and detectivity to response time ratio values were found to be $0.01 \mathrm{nA}, \sim 1012$ Jones, $0.97 \mathrm{~ms}$, and $\sim 1012$, respectively [68]. $\mathrm{Cs}_{2} \mathrm{AgInCl}_{6}$ could also be synthesized using a solid-state reaction method in 2017, and single crystals were grown using a slow cooling method [65].

In double perovskites it is possible to achieve a direct to indirect bandgap transition by chemically adjusting the desired composition to modify the conduction band and its optoelectronic properties. For example, the incorporation of $\mathrm{Na}$ into $\mathrm{Cs}_{2} \mathrm{AgInCl}_{6}$ has been found to lead to an increase in PL by three orders of magnitude [38]. A device based on $\mathrm{Cs}_{2} \mathrm{Ag}_{0.60} \mathrm{Na}_{0.40} \mathrm{InCl}_{6}$ (Bi doped: $0.04 \%$ ) showed a PLQY of $86( \pm 5) \%$, which was the highest PLQY for the already-reported white-light-emitting materials. $\mathrm{Cs}_{2} \mathrm{Ag}_{0.60} \mathrm{Na}_{0.40} \mathrm{InCl}_{6}$ resulted in a bright and broad PL emission peak around $550 \mathrm{~nm}$ which covered a large region of the visible spectrum. This material with $40 \% \mathrm{Na}$ was stable and could work for over 1000 hours. Upon further increasing the Na content, the efficiency decreased, which may be due to the decreased transition dipole moment and enhancement of non-radiative loss of photoexcited electrons through recombination with holes [38]. Visible light emission properties of $\mathrm{Cs}_{2} \mathrm{AgInCl}_{6}$ were also improved by Mn doping [70]. The doped product showed strong PL emission at $\sim 632 \mathrm{~nm}$ 
(Figure 10a,b). PL intensity increased linearly by increasing the concentration of Mn from $0.1 \%$ to $0.9 \%$. There was no change in the bandgap in $\mathrm{Mn}$-doped $\mathrm{Cs}_{2} \mathrm{AgInCl}_{6}$. The doped perovskite exhibited a face-centered cubic geometry group. It showed thermal stability up to $525^{\circ} \mathrm{C}$. Thus, lattice ion doping in $\mathrm{Cs}_{2} \mathrm{AgInCl}_{6}$ can enhance its optical emission properties. Lattice ion doping of other transition elements is also believed to be able to tune up the bandgap and photophysical properties.
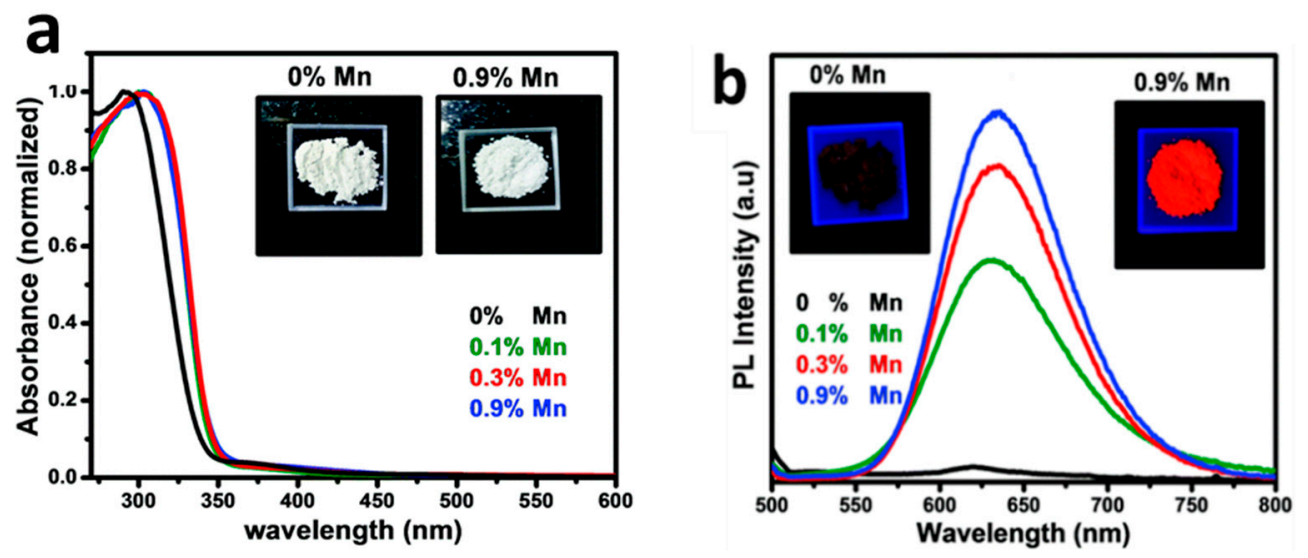

Figure 10. (a) UV-visible absorption of $\mathrm{Mn}$-doped $\mathrm{Cs}_{2} \mathrm{AgInCl}_{6}$ with different $\mathrm{Mn}$ contents. Insets show photographs of white-colored powder samples under visible light. (b) PL spectra of Mn-doped $\mathrm{Cs}_{2} \mathrm{AgInCl}_{6}$ with different $\mathrm{Mn}$ contents after excitation with $340 \mathrm{~nm}$ light. Insets show photographs of luminescence from the powder samples under UV light. Reproduced with permission from [70].

Double perovskites possess inversion symmetry, as depicted by their crystal structure. Generally, the compounds with inversion symmetry show parity-forbidden transitions between the conduction and valence band. Detailed studies on semiconducting materials like $\mathrm{CuM}^{2+} \mathrm{O}_{2}\left(\mathrm{M}^{2+}=\mathrm{In}, \mathrm{Ga}, \mathrm{Al}\right)[71]$, $\mathrm{In}_{2} \mathrm{O}_{3}$ [72], $\mathrm{Tl}_{2} \mathrm{O}_{3}$ [73] and $\mathrm{SnO}_{2}$ [74] suggest that these materials possess inversion symmetry which leads to parity-forbidden transitions, which explains their large bandgaps. The inversion symmetry of double perovskites has provoked research efforts to find the parity-forbidden transitions in direct bandgap double perovskites and their relationships to the perovskites' optical properties. Studies on the direct bandgap material $\mathrm{Cs}_{2} \mathrm{AgInCl}_{6}$ explain the difference between its bandgap value $(\sim 3.3 \mathrm{eV})$ and the PL peak, which was observed at $608 \mathrm{~nm}(2.0 \mathrm{eV})$. The PL peak of white-colored $\mathrm{Cs}_{2} \mathrm{AgInCl}_{6}$ at $608 \mathrm{~nm}$ suggests that the product should be an orange color. This phenomenon can be explained by the parity-forbidden transitions between conduction band minimum and valence band maximum at the $\Gamma$ point and the low matrix elements at this point $\Gamma$ leading to a weak PL emission. Thus, the difference in the bandgap and PL emission peak has been found to be due to parity-forbidden transitions. These transitions may also increase the carrier lifetime of double perovskites, as in $\mathrm{Cs}_{2} \mathrm{AgInCl}_{6}(6 \mu \mathrm{s})$ [75]. Thus, double perovskites which have parity-forbidden transitions in the band structure show weak disrupted PL emissions and longer carrier lifetimes than double perovskites with parity-allowed-transitions. The study of anion diffusion in $\mathrm{Cs}_{2} \mathrm{AgInCl}_{6}$ revealed that it has low $\mathrm{Cl}$ vacancy formation energy. This energy is lowered by an empty s orbital of $\mathrm{In}^{3+}$, as shown in Figure 11 [54]. Hence, the electronic configuration of the metal cation at the B site should be considered a barrier in halide ion diffusion in double perovskites. Halide diffusion studies of double perovskites may support understanding of their optoelectronic properties. 

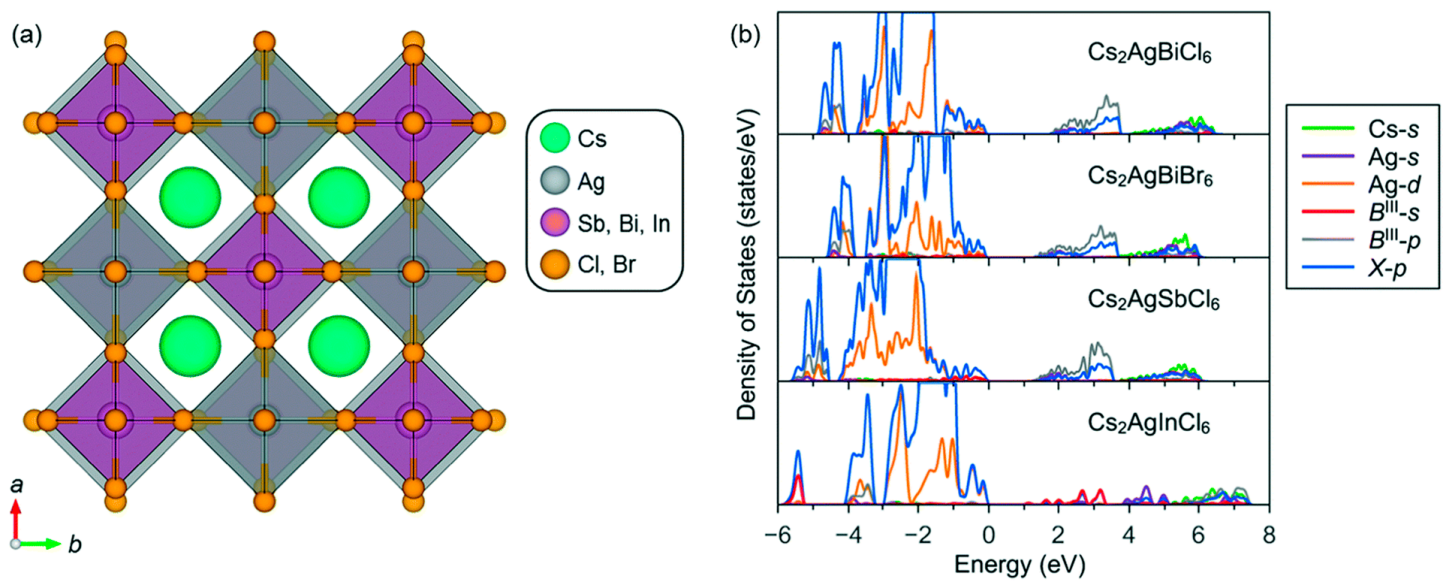

Figure 11. (a) Schematic crystal structure and (b) partial density of states of lead-free halide double perovskites $\mathrm{Cs}_{2} \mathrm{AgBiX}_{6}(\mathrm{X}=\mathrm{Cl}, \mathrm{Br}), \mathrm{Cs}_{2} \mathrm{AgSbCl}_{6}$, and $\mathrm{Cs}_{2} \mathrm{AgInCl}_{6}$. Reproduced with permission from [54].

\section{5. $\mathrm{Cs}_{2} \operatorname{AgTlX}_{6}(\mathrm{X}=\mathrm{Cl}, \mathrm{Br})$}

Incorporation of $\mathrm{Tl}$ as a trivalent metal into $\mathrm{A}_{2} \mathrm{~B}^{\prime} \mathrm{B}^{\prime \prime} \mathrm{X}_{6}$ could also tune the bandgap and increase the stability. $\mathrm{Cs}_{2} \mathrm{AgTlBr}_{6}$ and $\mathrm{Cs}_{2} \mathrm{AgTlCl}_{6}$ were synthesized using a hydrothermal approach [76]. The crystals were grown by slow cooling of preheated clear solutions from $100{ }^{\circ} \mathrm{C}$ to room temperature. These double perovskites crystallize in a cubic system with $F m \overline{3} m$ symmetry. The $\mathrm{Ag}-\mathrm{X}$ bond distances are similar to $\mathrm{Ag}-\mathrm{X}$ bonds in $\mathrm{Cs}_{2} \mathrm{AgBiX}{ }_{6}$ perovskites. However, $\mathrm{Tl}-\mathrm{X}$ bonds are $0.1 \AA$ shorter in length than $\mathrm{Bi}-\mathrm{X}$ bonds. $\mathrm{Cs}_{2} \mathrm{AgTlBr}_{6}$ has a $2.0 \mathrm{eV}$ direct bandgap while $\mathrm{Cs}_{2} \mathrm{AgTlCl}_{6}$ has the lowest direct bandgap value of $0.95 \mathrm{eV}$. These compounds showed a lack of PL phenomena. It was also shown that $\mathrm{Cs}_{2} \mathrm{AgTlBr}_{6}$ crystals grown in a bromine-free environment show more conductivity than crystals grown in a bromine environment. $\mathrm{Cs}_{2} \mathrm{AgTlBr}_{6}$ was found to be stable for more than 40 days under ambient conditions.

\section{6. $\mathrm{Cs}_{2} \mathrm{NaVCl}_{6}$}

Very recently $\mathrm{Cs}_{2} \mathrm{NaVCl}_{6}$ was synthesized using a solid-state reaction method. Crystals $\sim 1 \mathrm{~mm}$ in size were grown using a hydrothermal approach in $\mathrm{HCl}$ [77]. This new double perovskite with vanadium (III) in the $\mathrm{B}$ position and $\mathrm{Na}$ in the $\mathrm{B}^{\prime}$ position was synthesized from $\mathrm{VCl} / \mathrm{V}_{2} \mathrm{O}_{3}, \mathrm{CsCl}$, and $\mathrm{NaCl}$ precursors. The solution was heated for hydrothermal product formation at a temperature of $150{ }^{\circ} \mathrm{C}$ in a Teflon-lined autoclave for $2-4 \mathrm{~h}$. This double perovskite had a bandgap of $\sim 2.64 \mathrm{eV}$ as calculated from UV-visible diffuse reflectance spectra, which showed two strong peaks at 558 and $900 \mathrm{~nm}$. These two absorption peaks were attributed to the electronic states and transitions of $\mathrm{V}^{3+}$ and seemed to be the characteristic peaks of the $\mathrm{Cs}_{2} \mathrm{NaVCl}_{6}$ double perovskite only. This double perovskite was found to be thermally stable up to $650{ }^{\circ} \mathrm{C}$ and to decompose through two different pathways. It was also stable under ambient conditions and was relatively more stable than hybrid perovskites.

\subsection{Organic-Inorganic Hybrid Halide Double Perouskites}

In 2016, Deng et al. tried to explore new double perovskites that have a similar bandgap to lead perovskites. By using density functional theory, they predicted that organic-inorganic hybrid $(\mathrm{MA})_{2} \mathrm{~B}^{\prime} \mathrm{BiX}_{6}$ type structures could be synthesized if $\mathrm{K}, \mathrm{Cu}, \mathrm{Tl}$, or $\mathrm{Ag}$ is incorporated at the $\mathrm{B}^{\prime}$ position and $\mathrm{Br}, \mathrm{Cl}$, or $\mathrm{I}$ at the $\mathrm{X}$ position. $(\mathrm{MA})_{2} \mathrm{~B}^{\prime} \mathrm{BiX}_{6}$ has a similar bandgap to $\mathrm{MAPbX}_{3}$. They succeeded in the synthesis of $(\mathrm{MA})_{2} \mathrm{TlBiBr}_{6}$, which was found to have a bandgap of $\sim 2.0 \mathrm{eV}$, by using a hydrothermal method, as shown in Figure 12. This dark-red-colored double perovskite crystal has $\mathrm{Tl}^{+}$ and $\mathrm{Bi}^{3+}$ alternating at the octahedral positions like $\mathrm{Pb}^{2+}$ in $\mathrm{MAPbX}_{3}$. This opens up the possibility of synthesizing lead-alternative perovskites with similar properties to $\mathrm{MAPb}_{\mathrm{X} 3}$ [78]. 

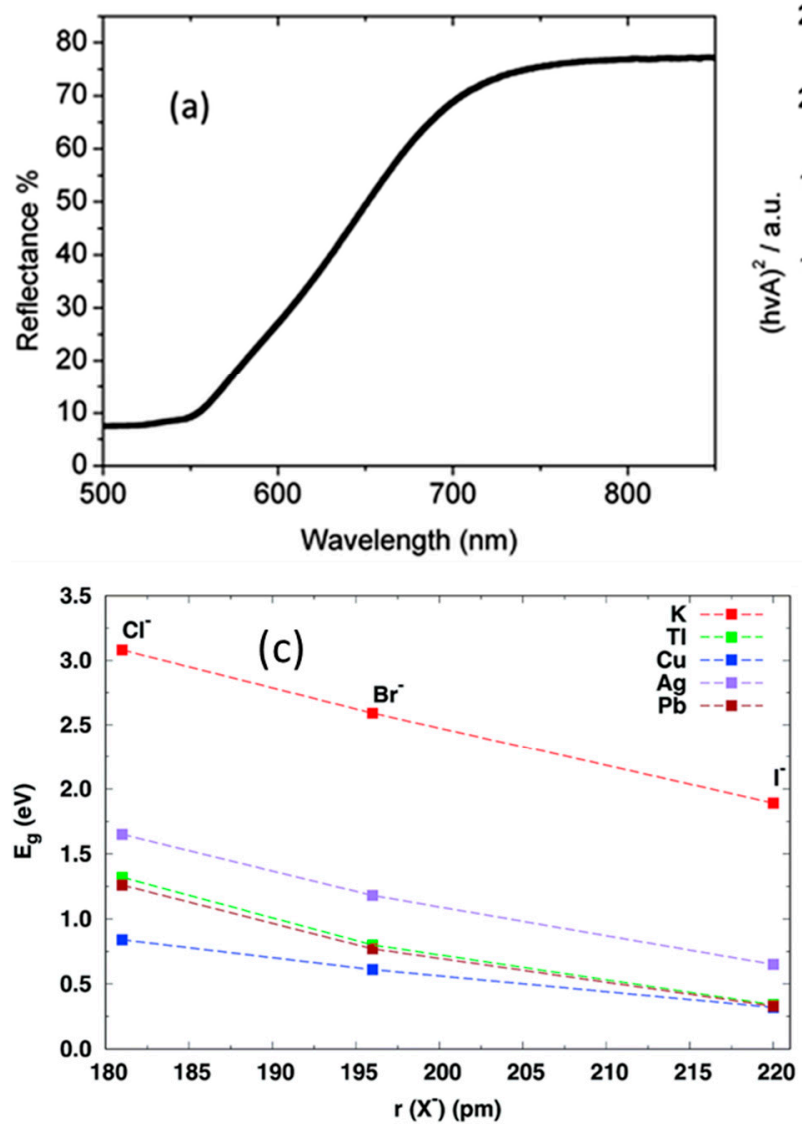
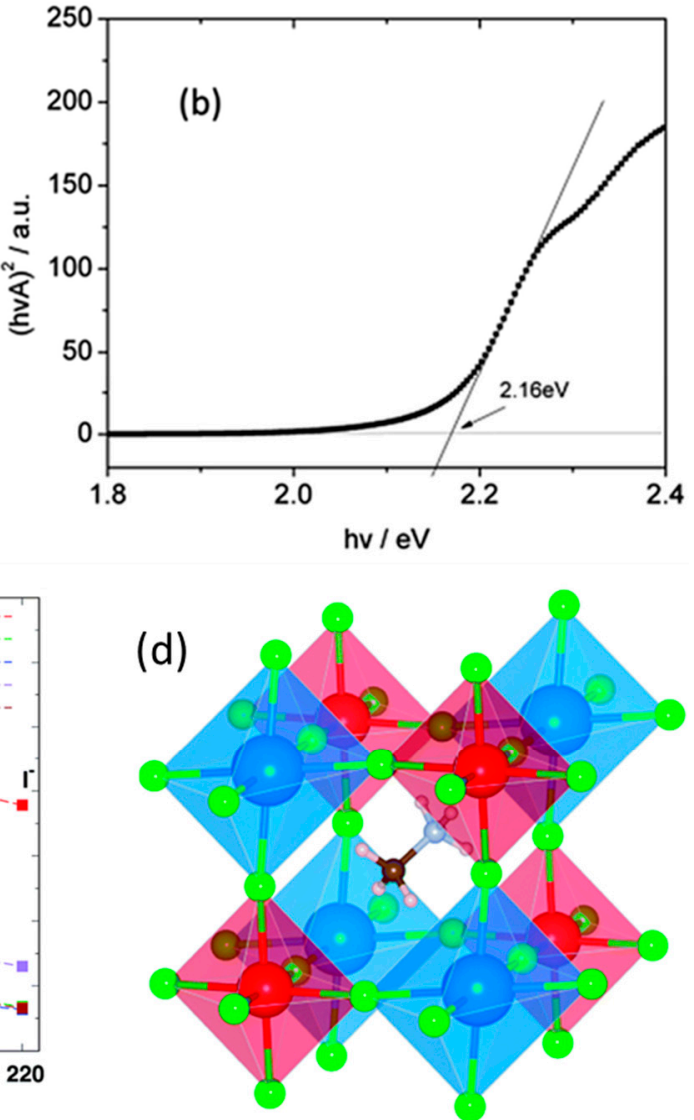

Figure 12. (a) Reflectance spectra. (b) Bandgap. (c) Computed bandgaps of $(\mathrm{MA})_{2} \mathrm{BIBiX}_{6}$ where $\mathrm{BI}=\mathrm{K}$, $\mathrm{Tl}, \mathrm{Cu}$, or $\mathrm{Ag}$ as a function of the $\mathrm{X}$ anion radius, including the $\mathrm{MAPbX}_{3}$ reference structures. (d) Crystal structure of $(\mathrm{MA})_{2}$ BIBIIIX $_{6}$. Blue: BI; red: BIII; pink: H; brown: C; grey: N; green: X. BIX6 and BIIIX6 octahedra are shown in blue and red, respectively. Reproduced with permission from [78].

Lead-based perovskites and halide double perovskites mostly crystallize in a cubic unit cell lattice. However, they can exist in other crystal systems, e.g., rhombohedral geometry [79]. Wei et al. reported the hybrid double perovskite (MA) ${ }_{2} \mathrm{KBiCl}_{6}$ with an indirect bandgap of $3.04 \mathrm{eV} \mathrm{[80].} \mathrm{It} \mathrm{was} \mathrm{synthesized}$ using a hydrothermal method and its crystal structure depicted rhombohedral geometry with an $R \overline{3} m$ space group, as shown in Figure 13. The compound was stable up to $503 \mathrm{~K}$ as evidenced by TGA testing. $\mathrm{Li}$ et al. synthesized the hybrid double perovskite (MA) ${ }_{2} \mathrm{AgSbI}_{6}$ in 2017 using a solid-state reaction [81]. This perovskite absorbed in the 200-600 nm UV-visible range and had a $1.93 \mathrm{eV}$ indirect bandgap. The (MA) ${ }_{2} \mathrm{AgSbI}_{6}$ was stable for 370 days under ambient conditions and started decomposition at $260{ }^{\circ} \mathrm{C}$. It showed better stability than the corresponding $\mathrm{Pb}$-based perovskite $\mathrm{MAPbI}_{3}$.
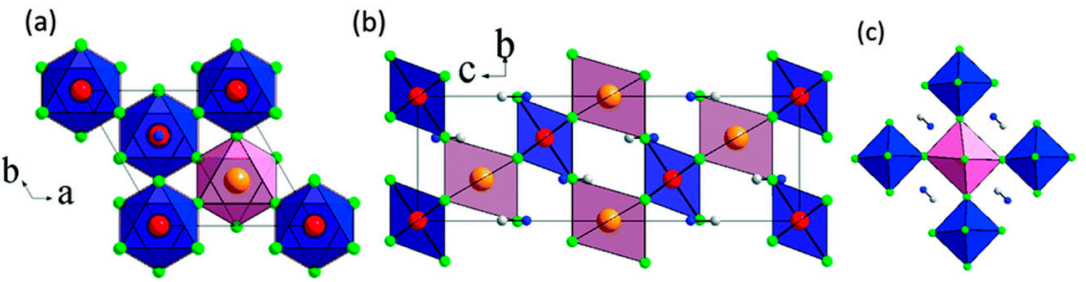

Figure 13. Crystal structure of $(\mathrm{MA})_{2} \mathrm{KBiCl}_{6}$ along different axes. Red: Bi; brown: K; green: Cl; white: $\mathrm{C}$; blue: $\mathrm{N}$. $\mathrm{BiCl}_{6}$ and $\mathrm{KCl}_{6}$ octahedra are shown in blue and purple, respectively. Reproduced with permission from [80]. 
Volonakis et al. found (theoretically) some potential organic-inorganic hybrid double perovskites which could be $\mathrm{MAPbI}_{3}$ alternatives [82]. Hypothetical double perovskites with structures $\mathrm{MA}_{2} \mathrm{InBiBr}_{6}$, $\mathrm{FA}_{2} \mathrm{InBiBr}_{6}$, and mixed-cation $(\mathrm{Cs} / \mathrm{MA} / \mathrm{FA})_{2} \operatorname{InBiBr}_{6}$ were proposed. Increasing the size of the cation by alternating $\mathrm{Cs}^{+}$with $\mathrm{MA}^{+} / \mathrm{FA}^{+}$in double perovskites can enhance stability. It can control the oxidation of unstable $\mathrm{B}^{+}\left(\mathrm{In}^{+}\right)$to the $\mathrm{B}^{3+}\left(\mathrm{In}^{3+}\right)$ metal cation (Figure 14$)$. This approach could prove hybrid double perovskites to be a stable and non-toxic alternative toMAPbI . Unfortunately, some efforts regarding the synthesis of organic-inorganic hybrid $\mathrm{A}_{2} \operatorname{InBiBr}_{6}(\mathrm{~A}=\mathrm{MA}, \mathrm{FA})$ were not successful. The successful synthesis of direct bandgapped stable hybrid double perovskites is expected to largely expand the family of halide double perovskites.

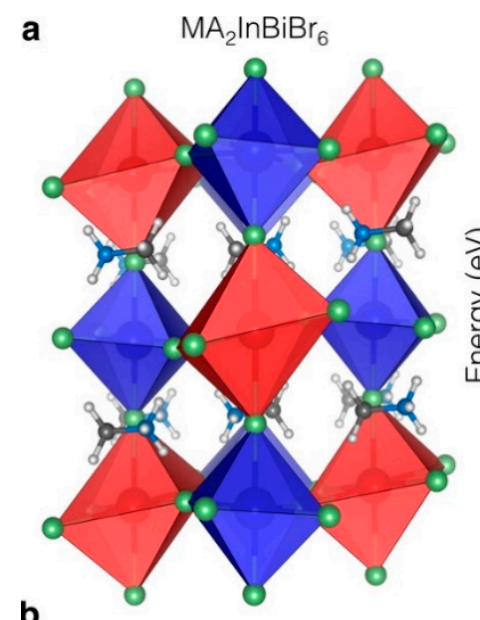

b

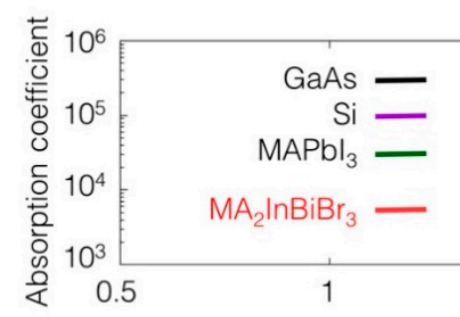

C

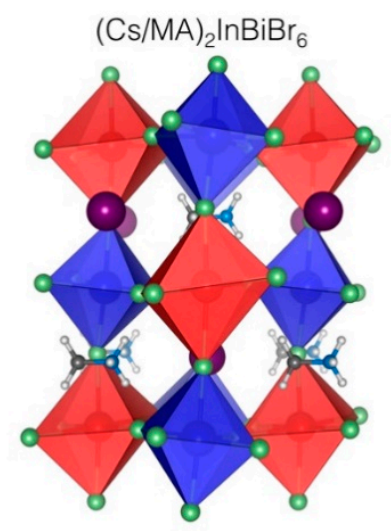

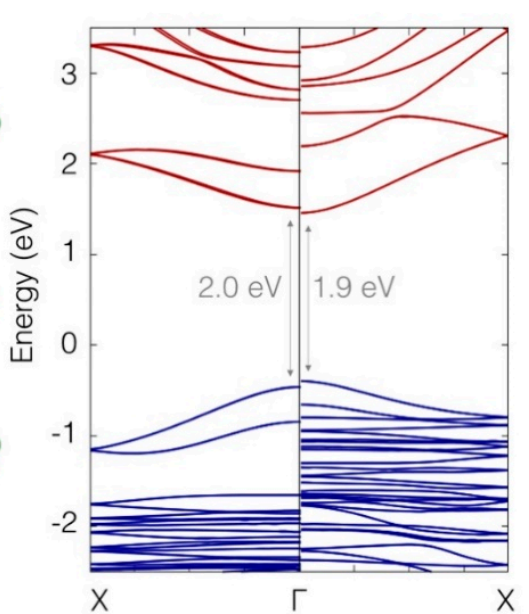



Wavevector
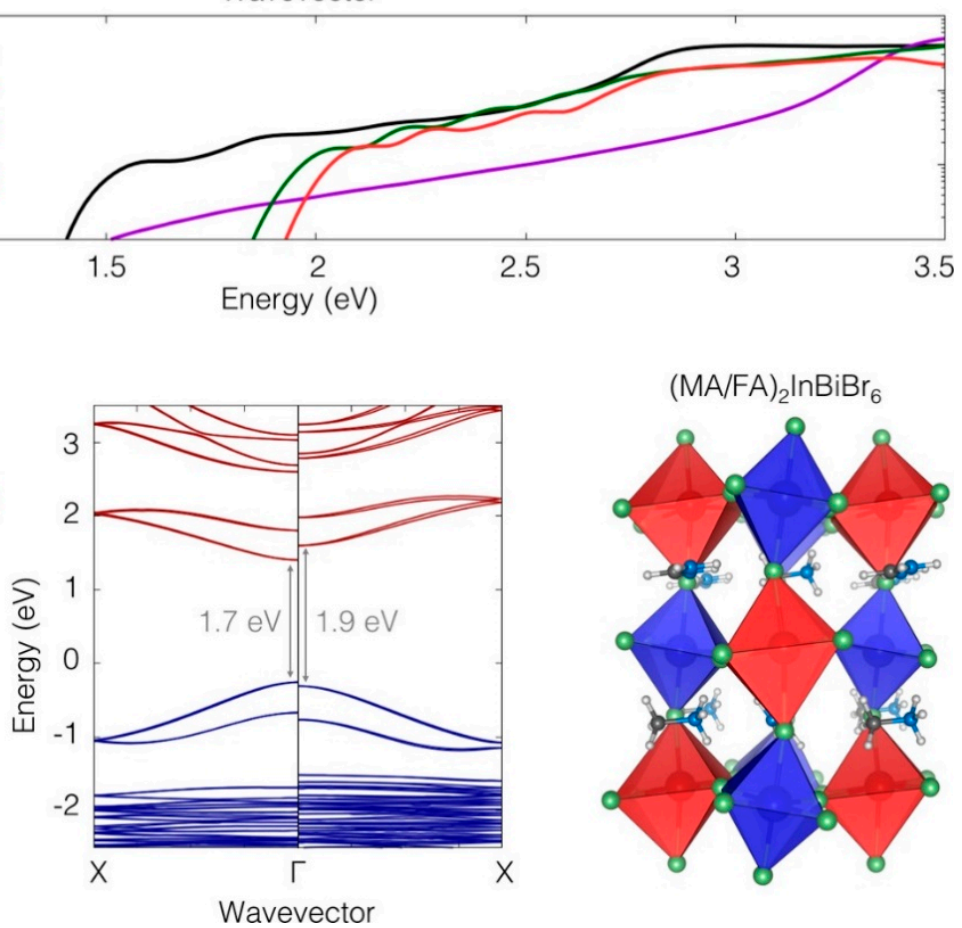

Figure 14. Electronic and optical properties of hypothetical halide double perovskites $\mathrm{MA}_{2} \operatorname{InBiBr}_{6}$, $(\mathrm{Cs} / \mathrm{MA})_{2} \mathrm{InBiBr}_{6}$, and $(\mathrm{MA} / \mathrm{FA})_{2} \operatorname{InBiBr}_{6}$. (a) Ball-stick octahedra models of the optimized structures and band structures of $\mathrm{MA}_{2} \mathrm{InBiBr}_{6}$ (left) and $\mathrm{MAPbI}_{3}$ (right). (b) Calculated optical absorption coefficients of $\mathrm{MA}_{2} \mathrm{InBiBr}_{6}$ (red), $\mathrm{Si}$ (purple), GaAs (black), and $\mathrm{MAPbI}_{3}$ (green). (c) Same as in (a) but for $(\mathrm{Cs} / \mathrm{MA})_{2} \mathrm{InBiBr}_{6}$ and $(\mathrm{MA} / \mathrm{FA})_{2} \operatorname{InBiBr}_{6}$. Reproduced with permission from [82]. 


\section{2D Halide Double Perovskites}

Electronic and physical properties of halide double perovskites depend on the dimensionality of their structure. It was found that the 3D structure of double perovskites can be altered into a 2D layered structure by introduction of some spacers. The layered structure belongs to either of the two types, namely, the Ruddlesden-Popper or Dion-Jacobson ordering, as shown in Figure 15 [83]. The 2D double perovskites' properties are different from those of their 3D analogues. Generally, 2D halide double perovskites have a direct bandgap, electronic diversity, and composition tunability. It was also found (theoretically) that hybridization control of the $\mathrm{d}$ orbital of the metal and the $\mathrm{p}$ orbital of the halide can result in constructing 2D electronic structures in the 3D structure of perovskites [84].

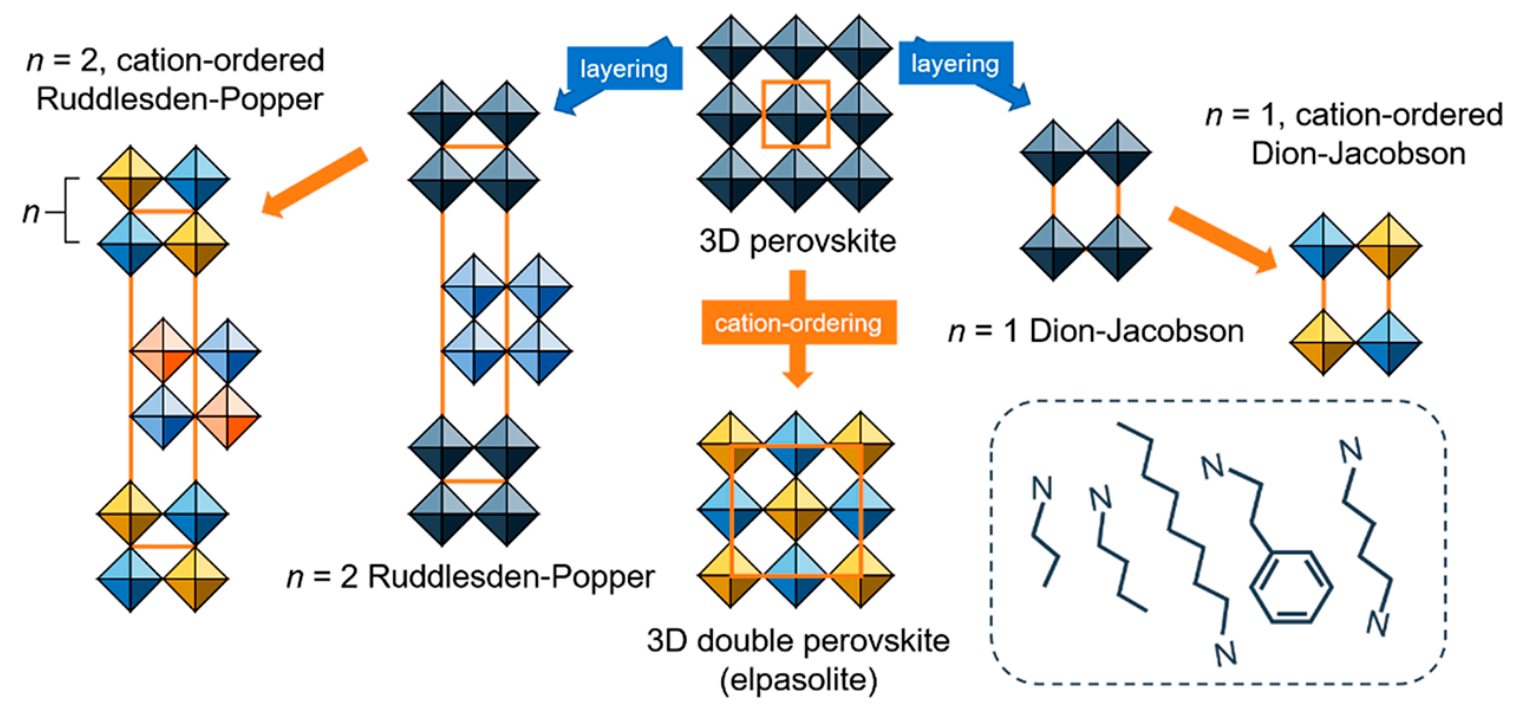

Figure 15. Schematic representation of the evolution of perovskites from a 3D structure to a 2D layered structure through the introduction of organic spacers. Reproduced with permission from [83].

In 2018, Karunadasa et al. synthesized 2D analogues of $3 \mathrm{D} \mathrm{Cs}_{2} \mathrm{AgBiBr}_{6}$ and studied the effects of reducing the dimensions [85]. They replaced $\mathrm{Cs}$ with the organic ligand $\mathrm{BA}\left(\mathrm{BA}=\mathrm{CH}_{3}\left(\mathrm{CH}_{2}\right)_{3} \mathrm{NH}_{3+}\right)$. The newly synthesized $2 \mathrm{D}(\mathrm{BA})_{4} \mathrm{AgBiBr}_{8}$ and $(\mathrm{BA})_{2} \mathrm{CsAgBiBr}_{7}$ showed a direct bandgap due to the reduction in dimensions. This strategy increased the diversity and volume of the library of perovskites. This approach also opened up the possibility of replacement of inorganic cations with organic parts to confine the dimensions. Recently, large $(\mathrm{BA})_{2} \mathrm{CsAgBiBr}_{7}$ crystals $10 \times 10 \times 3 \mathrm{~mm}^{3}$ in size were grown using a slow temperature lowering method as depicted in Figure 16 [86]. (BA) ${ }_{2} \mathrm{CsAgBiBr}_{7}$ was found to have an optical absorption bandgap of $2.38 \mathrm{eV}$ and a trap state density of $4.2 \times 1010 \mathrm{~cm}^{-3}$. The $\mathrm{X}$-ray detector based on this double perovskite showed a marvelous sensitivity of $4.2 \mu \mathrm{C} \mathrm{Gyair}{ }^{-1} \mathrm{~cm}^{-2}$. Fang et al. studied the effect of pressure on the optical properties of $2 \mathrm{D}(\mathrm{BA})_{4} \mathrm{AgBiBr}_{8}$ [87]. Optical properties varied with increasing pressure. PL intensity increased when raising the pressure to $8.2 \mathrm{GPa}$. Pressure above 8.2 GPa resulted in a decrease in PL intensity and the PL peak completely disappeared at $24 \mathrm{GPa}$. This result showed that $2 \mathrm{D}$ halide double perovskites could be optically activated by increasing the pressure. 
(a)



(c)

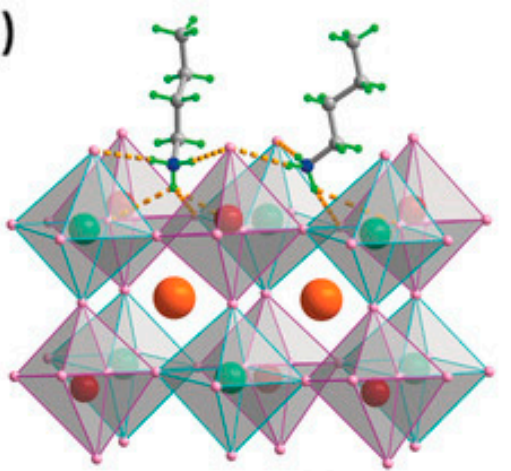

(b) Inorganic wells Inorganic wells Inorganic wells



Figure 16. (a) Photograph of as-grown single crystals of (BA $)_{2} \mathrm{CsAgBiBr}_{7}$. (b) Structural alignment of $(\mathrm{BA})_{2} \mathrm{CsAgBiBr}_{7}$ and octahedra of BA. Reproduced with permission from [86].

In another approach, two new $2 \mathrm{D}$ double perovskites $\left(\mathrm{C}_{6} \mathrm{H}_{16} \mathrm{~N}_{2}\right)_{2} \mathrm{AgBiI}{ }_{8} \cdot \mathrm{H}_{2} \mathrm{O}$ and $\left(\mathrm{C}_{6} \mathrm{H}_{16} \mathrm{~N}_{2}\right)_{2} \mathrm{CuBiI}_{8^{*} 0.5} \mathrm{H}_{2} \mathrm{O}$ were synthesized [88]. These perovskites had bandgaps of $1.93 \mathrm{eV}$ and $1.68 \mathrm{eV}$, respectively. Both of them crystallized in a P21/c space group with a 2D structure, as shown in Figure 17. $\left(\mathrm{C}_{6} \mathrm{H}_{16} \mathrm{~N}_{2}\right)_{2} \mathrm{AgBiI} 8 \cdot \mathrm{H} 2 \mathrm{O}$ showed an absorption peak in the UV-visible spectra around $2.15 \mathrm{eV}$ and PL emission at $1.84 \mathrm{eV} .\left(\mathrm{C}_{6} \mathrm{H}_{16} \mathrm{~N}_{2}\right)_{2} \mathrm{CuBiI}_{8 \cdot 0.5} \mathrm{H}_{2} \mathrm{O}$ absorbed at $2.02 \mathrm{eV}$ and showed a PL peak at $1.78 \mathrm{eV}$.

(a)

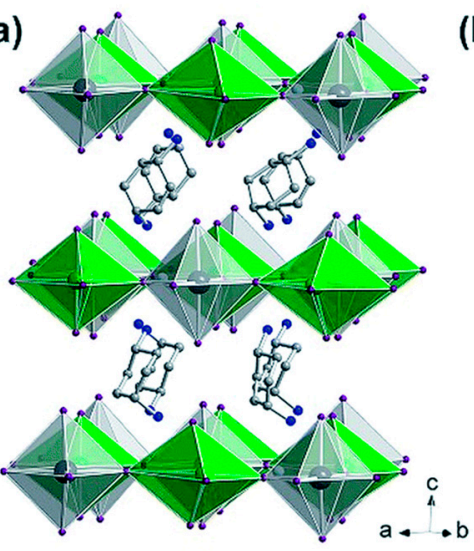

(b)



Figure 17. Crystal structure of (a) $\left(\mathrm{C}_{6} \mathrm{H}_{16} \mathrm{~N}_{2}\right)_{2} \mathrm{AgBiI} \cdot \mathrm{H}_{2} \mathrm{O}$ and (b) $\left(\mathrm{C}_{6} \mathrm{H}_{16} \mathrm{~N}_{2}\right)_{2} \mathrm{CuBiI}_{8} \cdot 0.5 \mathrm{H}_{2} \mathrm{O}$. Reproduced with permission from [88].

Recently, seven new double perovskites, namely, $\mathrm{PA}_{4} \mathrm{AgInCl}_{8}, \mathrm{PA}_{4} \mathrm{AgBiBr}_{8}$, and $\mathrm{PA}_{4} \mathrm{AgInBr}_{8}$, where

$\mathrm{PA}$ stands for propyl-ammonium, and $\mathrm{OCA}_{4} \mathrm{AgBiBr}_{8}, \mathrm{BDA}_{2} \mathrm{AgBiBr}_{8}, \mathrm{PA}_{2} \mathrm{CsAgBiBr}_{7}$, and 
$\mathrm{PA}_{2} \mathrm{CsAgIn}_{0.5} \mathrm{Bi}_{0.5} \mathrm{Br}_{7}$, where OCA stands for octyl-ammonium and BDA for 1,4- butanediammonium, have been synthesized and characterized, as shown in Figure 18 [83].

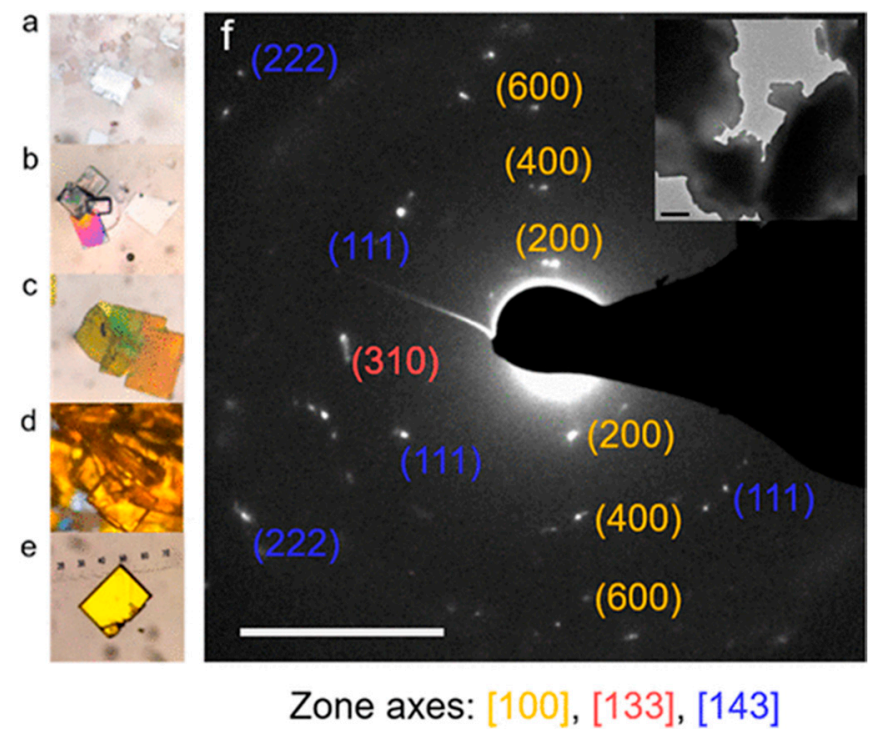

Figure 18. Optical microscope images of (a) $\mathrm{PA}_{4} \mathrm{AgInCl}_{8}$, (b) $\mathrm{PA}_{4} \mathrm{AgInBr}_{8}$ (colorless; , the purple comes from an interference effect), (c) $\mathrm{PA}_{4} \mathrm{AgBiBr}_{8}$, (d) $\mathrm{PA}_{2} \mathrm{CsAgBiBr}_{7}$, and (e) $\mathrm{PA}_{2} \mathrm{CsAgBi}_{0.5} \mathrm{Br}_{7}$. (f) Selected area electron diffraction (SAED) of fragments of $\mathrm{PA}_{4} \mathrm{AgBiBr}_{8}$, showing spots corresponding to the labeled d-spacings, with real-space TEM images of fragments inset. Scale bars: $2 \mathrm{~nm}^{-1}$ for the SAED image and $1 \mu \mathrm{m}$ for the real-space image. Inset shows d-spacing of $3.1 \AA$. Reproduced with permission from [83].

\section{Nanocrystals of Halide Double Perovskites}

Research advancements in the synthesis of nanocrystals (NCs) with desired morphology and optoelectronic applications of nanocrystalline materials have arisen since the 1980s. Perovskite nanocrystals exhibit many merits, including being solution phase processed, having a tunable bandgap, and showing defect tolerance. They show interesting optoelectronic properties such as high PL quantum yield, long carrier lifetime, high charge carrier mobility, and being compositionally tunable [89]. Zhou et al. reported the synthesis of $\mathrm{Cs}_{2} \mathrm{AgBiBr}_{6} \mathrm{NCs}$ for the first time using a hot injection method (Figure 19) [90]. It was found that the optimal temperature for NC synthesis was $200{ }^{\circ} \mathrm{C}$. The presence of oleic acid for nanocrystal formation, oleylamine for dissolving the $\mathrm{BiBr}_{3}$, and $\mathrm{HBr}$ for fully ionizing $\mathrm{Ag}^{+}$was necessary. 


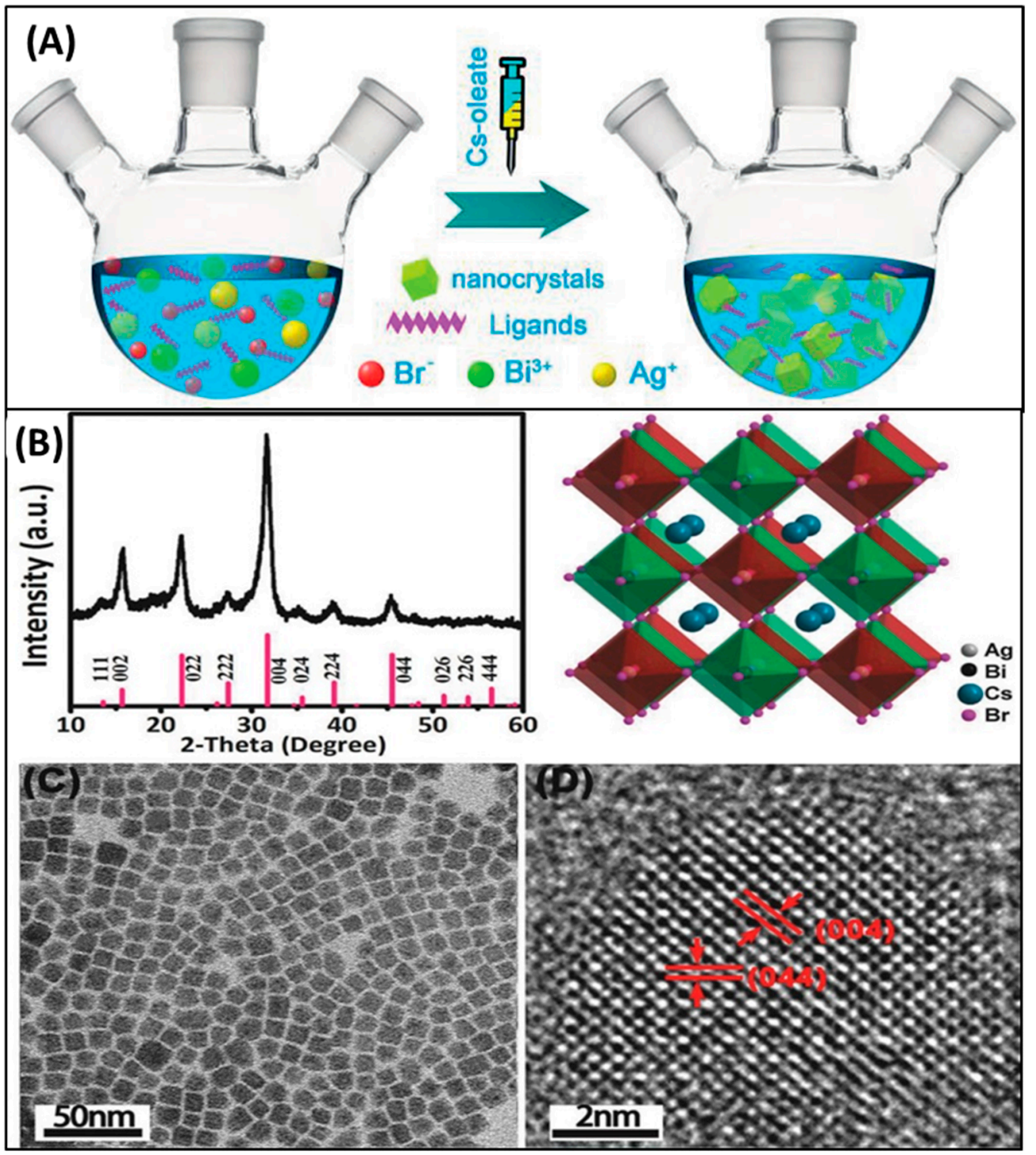

Figure 19. (a) Schematic illustration of solution phase synthesis of $\mathrm{Cs}_{2} \mathrm{AgBiBr}_{6}$ Nanocrystals (NCs) (hot-injection route). (b) XRD pattern of $\mathrm{Cs}_{2} \mathrm{AgBiBr}_{6} \mathrm{NCs}$ synthesized at $200{ }^{\circ} \mathrm{C}$ and crystal structure of cubic $\mathrm{Cs}_{2} \mathrm{AgBiBr}_{6}$. (c,d) TEM and high-resolution TEM images of $\mathrm{Cs}_{2} \mathrm{AgBiBr}_{6} \mathrm{NCs}$. Reproduced with permission from [90].

As can be seen in Figure 19, synthesized halide double perovskite NCs were obtained with well-defined cubic shapes and were uniformly distributed with an average size of $9.5 \mathrm{~nm}$. Thus, double perovskite NCs could be obtained with uniform and well-defined shapes in a similar fashion to Pb-based NCs. The bandgap of the $\mathrm{Cs}_{2} \mathrm{AgBiBr}_{6} \mathrm{NCs}$ was $2.52 \mathrm{eV}$ and showed a blue shift of $0.57 \mathrm{eV}$ from the corresponding bulk $\mathrm{Cs}_{2} \mathrm{AgBiBr}_{6}(1.95 \mathrm{eV})$; the enlarged bandgap was attributed to the quantum confinement effect. These NCs readily decomposed in organic solvents like dimethyl formamide because of their ionic nature. They also degraded in protonic solvents because of the proton exchange between the solvent and ligands. However, the NCs were stable (lasting about three weeks) in mild polar (chloroform) and non-polar solvents. $\mathrm{CO}_{2}$ reduction using $\mathrm{Cs}_{2} \mathrm{AgBiBr}_{6}$ was carried out in non-protonic and mildly polar solvent ethyl acetate, as this has been reported recently as a medium for conducting the photocatalytic reduction of $\mathrm{CO}_{2}$ and because the NCs were found to be stable in it for five days [5]. 
$\mathrm{Cs}_{2} \mathrm{AgBiBr}_{6}$ and $\mathrm{Cs}_{2} \mathrm{AgBiCl}_{6}$ colloidal NCs were reported in 2017 followed by ion-exchange reactions to yield a new material, namely, $\mathrm{Cs}_{2} \mathrm{AgBiI}_{6}$. Nanocrystals were prepared by using trimethylsilyl halides as the ion exchange reagent, as depicted in Figure 20 [91]. $\mathrm{Cs}_{2} \mathrm{AgBiX}_{6}(\mathrm{X}=\mathrm{Cl}$, $\mathrm{Br}) \mathrm{NCs}$ were further explored via synthesis using two new methods and by studying their physical properties. In the first method, $8-15 \mathrm{~nm}$ sized NCs were synthesized by injecting the precursor solutions of octadecene along with oleylamine and oleic acid into the Cs-oleate and keeping the solution within the temperature range $150-200{ }^{\circ} \mathrm{C}$. The second method also yielded the same type of nanocrystals in which the reactants were injected into the metal acetate solutions at a comparatively low temperature, i.e., $100{ }^{\circ} \mathrm{C}$ [92]. $\mathrm{Cs}_{2} \mathrm{AgBiBr}_{6}$ showed a sharp absorption peak at $\sim 430 \mathrm{~nm}$, with an indirect transition which was also confirmed by PL observed at $650 \mathrm{~nm}$ with a full width at half maximum of $\sim 200 \mathrm{~nm}$. $\mathrm{Cs}_{2} \mathrm{AgBiCl}_{6}$ showed absorption at $365 \mathrm{~nm}$ with no PL emission peak.

The depletion of the double perovskite structure results in a phase transition from cubic $\mathrm{Cs}_{2} \mathrm{AgBiBr}_{6}$ to trigonal $\mathrm{Cs}_{3} \mathrm{Bi}_{2} \mathrm{Br}_{9}, \mathrm{Cs}_{3} \mathrm{BiBr}_{6}$, and elemental silver, as follows.

$$
3 \mathrm{Cs}_{2} \mathrm{AgBiBr}_{6} \rightarrow \mathrm{Cs}_{3} \mathrm{Bi}_{2} \mathrm{Br}_{9}+\mathrm{Cs}_{3} \mathrm{BiBr}_{6}+3 \mathrm{Ag}+3 / 2 \mathrm{Br}_{2}
$$

The spreading out of $\mathrm{Ag}$, together with its reduction and adjoining, is the key reason for structural instability. The $\mathrm{Cs}_{2} \mathrm{AgBiBr}_{6} \mathrm{NCs}$ are stable in polar solvents and were found to retain their phase in polar solvents. These NCs showed a similar absorption peak in polar solvents with a value of polar indices lower than 4.4 (ethyl acetate). For fast screening of reaction conditions and the expected properties, a microfluidic reactor was designed to synthesize the halide double perovskite NCs [93].

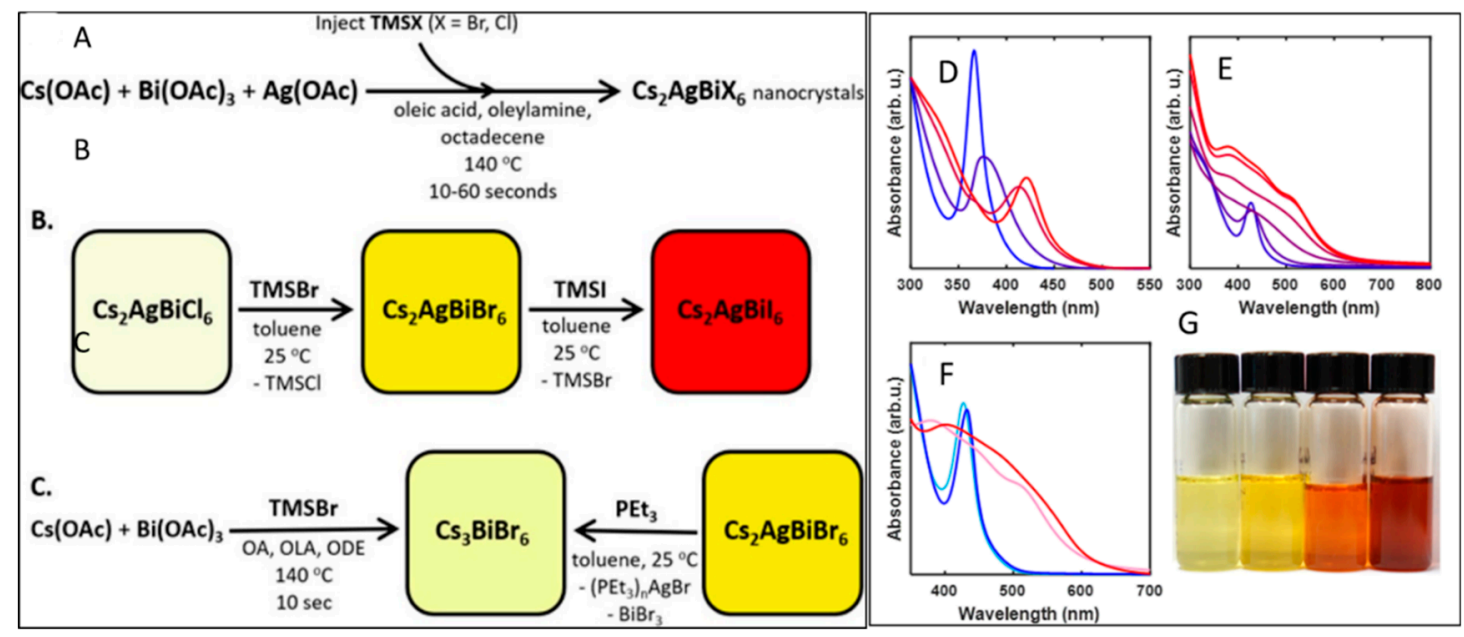

Figure 20. (a-c) Synthesis and reactivity of $\mathrm{Cs}_{2} \mathrm{AgBiX}_{6}$ nanocrystals. (d,e) Optical properties of synthesized nanocrystals. (f) Comparison of absorption spectra from two different sizes of $\mathrm{Cs}_{2} \mathrm{AgBiBr}_{6}$ nanocrystals (blue) and the corresponding anion-exchanged $\mathrm{Cs}_{2} \mathrm{AgBiI}_{6}$ (red) nanocrystals; starting diameters were $9 \mathrm{~nm}$ (light blue/light red) and $13 \mathrm{~nm}$ (dark blue/dark red). (g) Photograph of dilute toluene solutions of (left to right) $\mathrm{Cs}_{2} \mathrm{AgBiBr}_{6}, \mathrm{Cs}_{2} \mathrm{AgBiBr}_{5.2} \mathrm{I}_{0.8}, \mathrm{Cs}_{2} \mathrm{AgBiBr}_{1.6} \mathrm{I}_{4.4}$, and $\mathrm{Cs}_{2} \mathrm{AgBiI}_{6}$ nanocrystals. Reproduced with permission from [91]. Legend: TMS = trimethylsilyl.

It is necessary to mention here that the size of the nanocrystals and their quantum confinement depends on the reaction conditions, and can be tuned accordingly [94]. Double perovskite NCs can be doped with some external metal like magnetic $\mathrm{Mn}^{2+}$ for modification of their optical properties [41,95]. This also paves the way for doping double perovskite NCs to obtain better magneto-optical applications in the near future. NCs offer a diverse area of research for scientists to improve the optoelectronic and magnetic performance of NCs within by size control and quantum confinement through controlling and modifying the synthetic methods, varying the composition of the perovskite structure, alloying metals, doping various metals and non-metals, and combining with other materials like carbon 
materials for better performances. It was observed that double perovskite structures which are not stable in the bulk state can be synthesized in nano-form with enhanced stability because of the considerable contribution of surface energy to the total energy balance in nanomaterials. Various synthetic approaches, detailed comparative synthetic parameters, and properties of nanocrystals of metal halide perovskites have been described recently by Shamsi and co-workers [96]. Nanoscale double perovskites can be further tuned by doping and substitutions of metal ions to enhance the optoelectronic response. For example, Yang et al. synthesized $\mathrm{Cs}_{2} \mathrm{AgIn}_{0.9} \mathrm{Bi}_{0.1} \mathrm{Cl}_{6} \mathrm{NCs}$ with a direct bandgap (Figure 21). PL quantum efficiency of $36.6 \%$ was achieved, which was comparable to lead-based perovskite NCs in the violet region of light [97]. Double perovskite NCs can also be explored for catalytic, sensor, and biological applications.
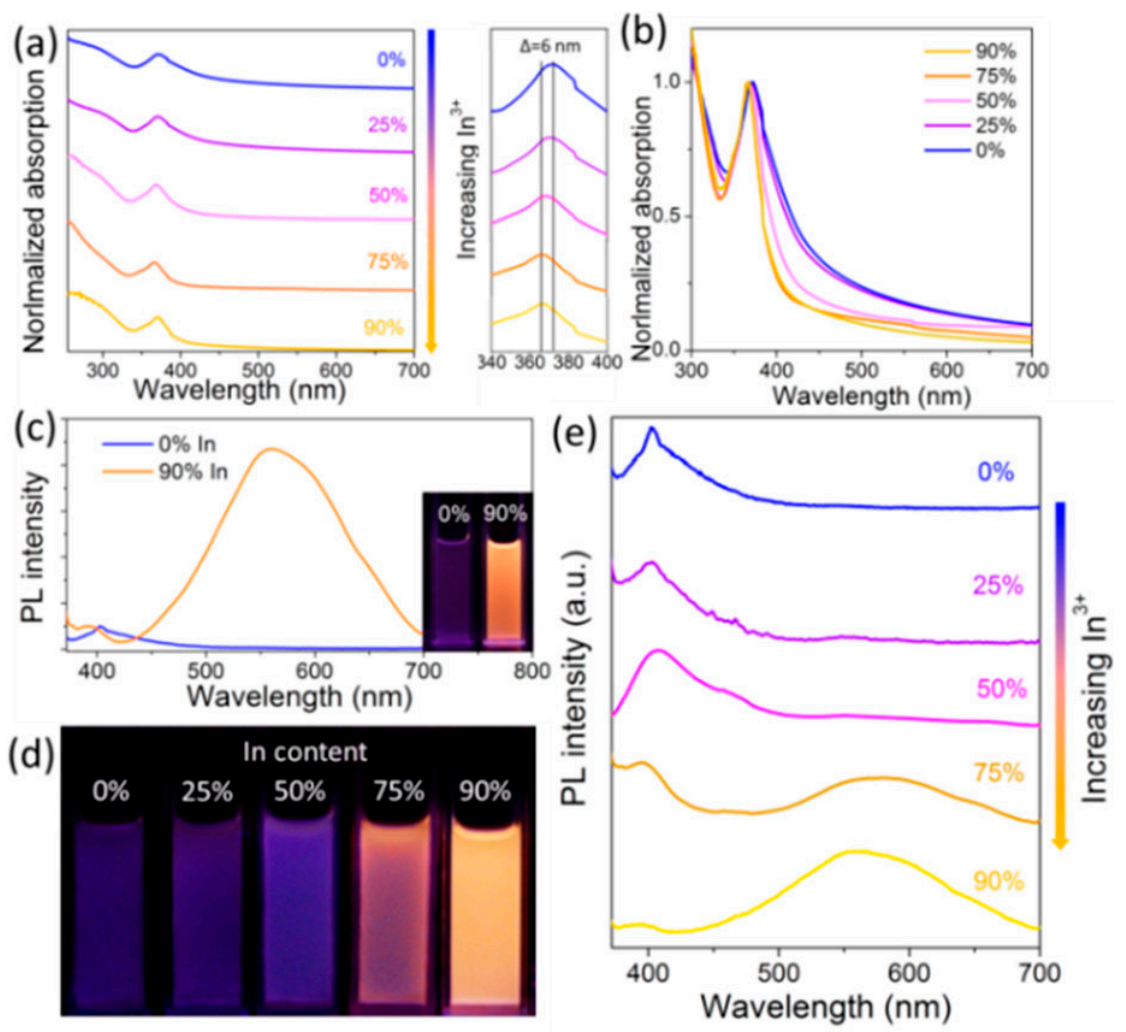

Figure 21. (a) Steady-state absorption spectra of ligand-free $\mathrm{Cs}_{2} \mathrm{AgIn}_{\mathrm{x}} \mathrm{Bi}_{1-\mathrm{x}} \mathrm{Cl}_{6}(\mathrm{x}=0,0.25,0.5,0.75$, and 0.9) NCs (left) and magnified portion of absorption spectra (right). (b) Normalized steady-state absorption spectra. (c) PL spectra of $\mathrm{Cs}_{2} \mathrm{AgIn}_{\mathrm{x}} \mathrm{Bi}_{1-\mathrm{x}} \mathrm{Cl}_{6}(\mathrm{x}=0$ and 0.9) NCs. (d) PL image under UV light of $365 \mathrm{~nm}$. (e) PL spectra. Reproduced with permission from [97].

In Table 1, some lead-free halide double perovskites and their properties are summarized. Halide double perovskites are synthesized by solution and solid-state methods. They are mostly crystallized in cubic crystal geometry with an $F m \overline{3} m$ space group. The bandgaps of these perovskites are tunable depending on their compositions. In 3D halide double perovskites, $\mathrm{Cs}_{2} \mathrm{AgInCl}_{6}$ shows a large bandgap of $3.23 \mathrm{eV}$ and $\mathrm{Cs}_{2} \mathrm{AgSbBr}_{6}$ shows a small bandgap of $1.64 \mathrm{eV}$. In $2 \mathrm{D}$ halide double perovskites, the bandgap varies from the largest value of $3.96 \mathrm{eV}$ for $\mathrm{PA}_{4} \mathrm{AgInCl}_{8}$ to the smallest value of $1.93 \mathrm{eV}$ for $(\mathrm{MA})_{2} \mathrm{AgSbI}_{6}$. Photophysical properties are probably composition-dependent in halide double perovskites. 
Table 1. Summary of some lead-free halide double perovskites and their properties.

\begin{tabular}{|c|c|c|c|c|c|c|}
\hline Double Perovskite & Crystal System & Space Group & Bandgap (eV) & PL $(\mathrm{eV})$ & Synthetic Method & Reference \\
\hline $\mathrm{Cs}_{2} \mathrm{AgBiBr}_{6}$ & Cubic & $F m \overline{3} m$ & 2.19 indirect & 1.87 & Hydrothermal & {$[21,49]$} \\
\hline $\mathrm{Cs}_{2} \mathrm{AgBiCl}_{6}$ & Cubic & $F m \overline{3} m$ & 2.77 indirect & 3.14 & Solid-state and hydrothermal & {$[21,61,98]$} \\
\hline$(\mathrm{MA})_{2} \mathrm{KBiCl}_{6}$ & Rhombohedral & $R \overline{3} m$ & 3.04 indirect & & Hydrothermal & [80] \\
\hline$(\mathrm{MA})_{2} \mathrm{TlBiBr}_{6}$ & Cubic & $F m \overline{3} m$ & $\sim 2.0$ direct & & Hydrothermal & [78] \\
\hline $\mathrm{Cs}_{2} \mathrm{AgInCl}_{6}$ & Cubic & $F m \overline{3} m$ & 3.23 direct & 1.95 & Solid-state and hydrothermal & {$[65,67,75]$} \\
\hline $\mathrm{Cs}_{2} \mathrm{AgSbCl}_{6}$ & Cubic & $F m \overline{3} m$ & 2.54-2.60 indirect & & Hydrothermal & {$[63,65]$} \\
\hline $\mathrm{Cs}_{2} \mathrm{AgIn}_{0.5} \mathrm{Sb}_{0.5} \mathrm{Cl}_{6}$ & & & 2.81 indirect & & Hydrothermal & [65] \\
\hline $\mathrm{Cs}_{2} \mathrm{AgSb}_{0.4} \mathrm{In}_{0.6} \mathrm{Cl}_{6}$ & & & 2.92 direct & & Hydrothermal & [65] \\
\hline $\mathrm{Cs}_{2} \mathrm{AgSb}_{0.2} \mathrm{In}_{0.8} \mathrm{Cl}_{6}$ & & & 3.06 direct & & Hydrothermal & [65] \\
\hline $\mathrm{Cs}_{2} \mathrm{NaVCl}_{6}$ & Cubic & $F m \overline{3} m$ & $\sim 2.64$ direct & & Solid-state & [77] \\
\hline $\mathrm{Cs}_{2} \mathrm{AgBi}_{1-\mathrm{x}} \mathrm{Sb}_{\mathrm{x}} \mathrm{Br}_{6}$ & Cubic & $F m \overline{3} m$ & $2-1.6$ & & Solid-state & [57] \\
\hline$(\mathrm{MA})_{2} \mathrm{AgSbI}_{6}$ & Cubic & $F m \overline{3} m$ & 1.93 & & Solid-state & [81] \\
\hline $\mathrm{Cs}_{2} \mathrm{AgSbBr}_{6}$ & Cubic & $F m \overline{3} m$ & 1.64 indirect & & Hydrothermal & [62] \\
\hline $\mathrm{Cs}_{2} \mathrm{NaBiCl}_{6}$ & Cubic & $F m \overline{3} m$ & & & Solvent evaporation & {$[44,45]$} \\
\hline $\mathrm{PA}_{4} \mathrm{AgInCl}_{8}$ & Triclinic & $P \overline{1}$ & 3.96 & & Hydrothermal & [83] \\
\hline $\mathrm{PA}_{4} \mathrm{AgBiBr}_{8}$ & Monoclinic & $C 2 / m$ & 2.41 & & Hydrothermal & [83] \\
\hline $\mathrm{PA}_{4} \mathrm{AgInBr}_{8}$ & Monoclinic & $C 2 / m$ & 3.15 & 2.76 & Hydrothermal & [83] \\
\hline $\mathrm{OCA}_{4} \mathrm{AgBiBr}_{8}$ & Monoclinic & $C 2 / m$ & & & Hydrothermal & [83] \\
\hline $\mathrm{BDA}_{2} \mathrm{AgBiBr}_{8}$ & Triclinic & $P \overline{1}$ & & & Hydrothermal & [83] \\
\hline $\mathrm{PA}_{2} \mathrm{CsAgBiBr}_{7}$ & Monoclinic & $C 2 / m$ & & & Hydrothermal & [83] \\
\hline $\mathrm{PA}_{2} \mathrm{CsAgIn}_{0.5} \mathrm{Bi}_{0.5} \mathrm{Br}_{7}$ & Monoclinic & $C 2 / m$ & & & Hydrothermal & [83] \\
\hline $\mathrm{PA}_{4} \mathrm{AgSb}_{0.5} \mathrm{Bi}_{0.5} \mathrm{Br}_{8}$ & & & 2.51 & 1.93 & Hydrothermal & [83] \\
\hline $\mathrm{PA}_{4} \mathrm{AgIn}_{0.5} \mathrm{Bi}_{0.5} \mathrm{Br}_{8}$ & & & 2.56 & 1.76 & Hydrothermal & [83] \\
\hline
\end{tabular}




\section{Applications of Halide Double Perovskites}

Halide double perovskites have been mainly explored in recent years for their optoelectronic applications. They have been applied in fabricating photodetectors [49,68], X-ray detectors [3,50], solar cells [19,29,32,37,51,63,67,99-101], LEDs [38,42], and photocatalysts [93], etc.

$\mathrm{Cs}_{2} \mathrm{AgBiBr}_{6}$-based thin film solar cells showed a PCE of $2.5 \%$ and an open current voltage larger than $1 \mathrm{~V}$, as illustrated in Figure 22 [102]. In another study, a $\mathrm{Cs}_{2} \mathrm{AgBiBr}_{6}$ based solar cell was fabricated with a uniform and compact perovskite thin film by optimizing the material deposition parameters, which led to the achievement of a $1.26 \%$ PCE [100]. $\mathrm{Cs}_{2} \mathrm{AgBiX}_{6} \mathrm{NCs}$ are also promising light-emitting materials. Yang et al. synthesized $\mathrm{Cs}_{2} \mathrm{AgBiX}_{6} \mathrm{NCs}$ and observed tunable PL emission from $2.15 \mathrm{eV}$ to $3.14 \mathrm{eV}$, as shown in Figure 23 [98]. Volonakis et al. studied the electronic surface properties of $\mathrm{Cs}_{2} \mathrm{BiAgCl}_{6}, \mathrm{Cs}_{2} \mathrm{BiAgBr}_{6}, \mathrm{Cs}_{2} \mathrm{SbAgCl}_{6}$, and $\mathrm{Cs}_{2} \mathrm{InAgCl}_{6}$ double perovskites and suggested that these materials have the potential for photocatalytic water splitting [103]. Ionization potential and electron affinity values of $\mathrm{Cs}_{2} \mathrm{BiAgCl}_{6}$ and $\mathrm{Cs}_{2} \mathrm{BiAgBr}_{6}$ indicate their promising potential for photocatalysis. It has also been speculated that composition with mixed halides can tune the photocatalytic activity as the conduction band level is controlled by halogen $p$ orbital energy.

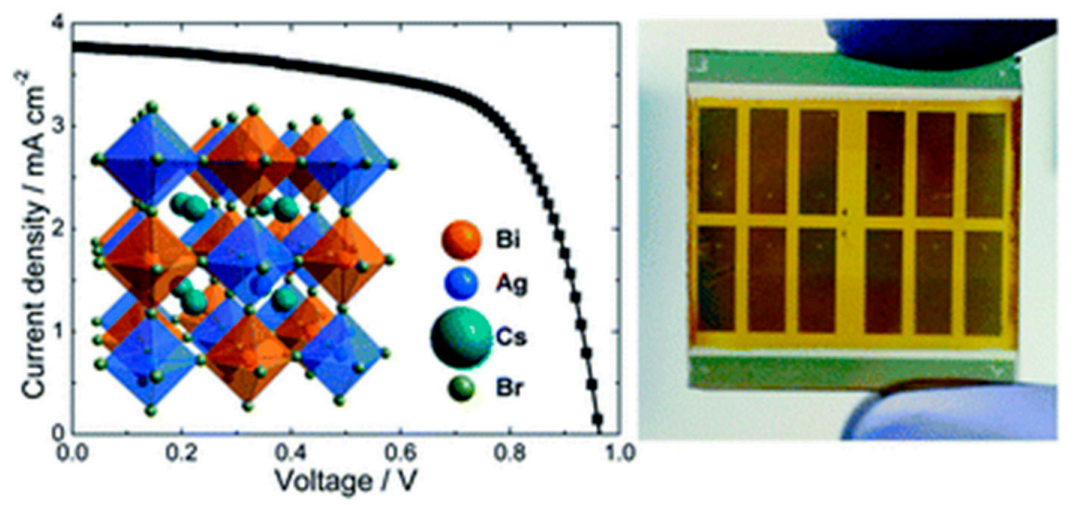

Figure 22. Performance of $\mathrm{Cs}_{2} \mathrm{AgBiBr}_{6}$-based thin film solar cell and optical image of the fabricated device. Reproduced with permission from [102].


Figure 23. (a) Steady-state absorption spectra $\mathrm{Cs}_{2} \mathrm{AgBiBr}_{6} \mathrm{NCs}$. (b) PL spectra NCs. Inset: photographs of colloidal ligand-free $\mathrm{Cs}_{2} \mathrm{AgBiBr}_{6} \mathrm{NCs}$. (c) Variation in relative PL and relative absorption. (d) Time-resolved photoluminescence (PL) kinetics of ligand-free NCs measured with time-correlated single photon counting ( $376 \mathrm{~nm}$ pump). (e) $\mathrm{NC}$ charge carrier dynamics. (f) XRD patterns of $\mathrm{Cs}_{2} \mathrm{AgBiX}_{6}$ $\mathrm{NCs}\left(\mathrm{X}=\mathrm{Cl}, \mathrm{Br}_{0.5} \mathrm{Cl}_{0.5}, \mathrm{Br}_{,} \mathrm{Br}_{0.5} \mathrm{I}_{0.5}, \mathrm{I}\right)$ and steady-state absorption and PL spectra of $\mathrm{Cs}_{2} \mathrm{AgBiX}_{6} \mathrm{NCs}$. Reproduced with permission from [98]. 
The NCs of $\mathrm{Cs}_{2} \mathrm{AgBiBr}_{6}$ have shown good results for reducing $\mathrm{CO}_{2}$ to sustainable fuels (CO and $\mathrm{CH}_{4}$ ) by showing an electron consumption of $105 \mu \mathrm{mol} \mathrm{g}{ }^{-1}$ (6 h) [93]. However, further improvement in stability by exploring different surface ligands and intercalations, or by different synthetic methods, is expected to improve NC stability and photocatalytic performance.

\section{Conclusions and Perspectives}

With beneficial properties such as their promising environmental friendliness, suitable compositional tunability, and favorable optoelectronic properties, halide double perovskites have stimulated increasing research interest in the materials science community. This review summarizes recent advances in the synthesis of $3 \mathrm{D}, 2 \mathrm{D}$, and nanocrystal representative $\mathrm{A}_{2} \mathrm{~B}^{\prime} \mathrm{B}^{\prime \prime} \mathrm{X}_{6}$ halide double perovskites. Important applications of these advanced materials in solar cells, photodetectors, $\mathrm{X}$-ray detectors, and photocatalysis, etc., are also introduced briefly. It can be seen that a variety of halide double perovskites with either a direct bandgap or an indirect bandgap have been demonstrated. Halide double perovskites with a bandgap comparable to that of the conventional $\mathrm{MAPbI}_{3}$ are now accessible, which may further boost the application of these less-toxic materials in the photovoltaic area. Although halide double perovskites were proposed initially to solve toxicity and stability issues of conventional $\mathrm{APbX}_{3}$ single perovskites, one of the current challenges in halide double perovskites is still their $1^{l}$ ower level of stability under ambient conditions and their low photovoltaic performance. Zhao et al. reported the degradation of single-perovskite-based optoelectronic devices in 2016. It was revealed that the perovskite device was degraded by redox reactions of the perovskite with $\mathrm{Ag}, \mathrm{Al}, \mathrm{Yb}$, or Cr layers. [104]. The degradation mechanism of double-perovskite-based optoelectronic devices is yet to be identified. Thus, there is a need to improve their stability and photoresponsivity, including photodetection, to overcome lead perovskites. The instability can be overcome by encapsulating the perovskite with carbon or by substitution of multi-cations or by incorporating the hydrophobic moieties around the perovskite structure [105]. The other challenge that is common to all perovskites is their large-scale application and commercialization. Furthermore, the change in bandgap with temperature in double perovskites was observed recently by Schade and co-workers. This might initiate further future temperature-dependent studies of double perovskites, as the bandgap of lead-based halide perovskites is temperature-independent [53]. In addition, large double perovskite crystals are more desired in applications. However, the crystal growth of large-sized $\mathrm{A}_{2} \mathrm{~B}^{\prime} \mathrm{B}^{\prime \prime} \mathrm{X}_{6}$ single crystals in a shorter time period is also a big challenge in this field. Overall, the double perovskite family has not been extensively explored yet and possible new combinations may provide alternative photovoltaic materials. In these double perovskites there are more chances of finding new perovskite combinations as the $\mathrm{B}^{\prime}$ and $\mathrm{B}^{\prime \prime}$ positions can be tuned to find the best combination for the best output. However, in these lead-free halide perovskites the exact mechanism of action relative to the particular structures is not yet known. Hence, there is sufficient research space, and we have enormous expectations for the future development of $\mathrm{A}_{2} \mathrm{~B}^{\prime} \mathrm{B}^{\prime \prime} \mathrm{X}_{6}$ halide double perovskite materials. The innovation and novelty in this field may surely find a solution for toxicity and instability.

Author Contributions: Q.Y. contributed to the conceptualization and writing of the manuscript; M.U. contributed to the writing of the manuscript. All authors have read and agreed to the published version of the manuscript.

Funding: This research was financially supported by the Science Challenge Project (TZ2018004), the National Natural Science Foundation of China (no. 21671115), the fund of the Innovation Center of Radiation Application (KFZC2018040204), and the Tsinghua University Initiative Scientific Research Program (2018Z05JZY022).

Conflicts of Interest: The authors declare no conflict of interest.

\section{References}

1. Sim, K.; Jun, T.; Bang, J.; Kamioka, H.; Kim, J.; Hiramatsu, H.; Hosono, H. Performance boosting strategy for perovskite light-emitting diodes. Appl. Phys. Rev. 2019, 6, 031402. [CrossRef]

2. Quan, L.N.; Rand, B.P.; Friend, R.H.; Mhaisalkar, S.G.; Lee, T.-W.; Sargent, E.H. Perovskites for next-generation optical sources. Chem. Rev. 2019, 119, 7444-7477. [CrossRef] [PubMed] 
3. Steele, J.A.; Pan, W.; Martin, C.; Keshavarz, M.; Debroye, E.; Yuan, H.; Banerjee, S.; Fron, E.; Jonckheere, D.; Kim, C.W. Photophysical pathways in highly sensitive $\mathrm{Cs}_{2} \mathrm{AgBiBr}_{6}$ double-perovskite single-crystal X-Ray detectors. Adv. Mater. 2018, 30, 1804450. [CrossRef] [PubMed]

4. $\quad$ Fang, Y.; Dong, Q.; Shao, Y.; Yuan, Y.; Huang, J. Highly narrowband perovskite single-crystal photodetectors enabled by surface-charge recombination. Nat. Photonics 2015, 9, 679. [CrossRef]

5. Xu, Y.-F.; Yang, M.-Z.; Chen, B.-X.; Wang, X.-D.; Chen, H.-Y.; Kuang, D.-B.; Su, C.-Y. A CsPbBr 3 perovskite quantum dot/graphene oxide composite for photocatalytic $\mathrm{CO}_{2}$ reduction. J. Am. Chem. Soc. 2017, 139, 5660-5663. [CrossRef] [PubMed]

6. Xing, G.; Mathews, N.; Lim, S.S.; Yantara, N.; Liu, X.; Sabba, D.; Grätzel, M.; Mhaisalkar, S.; Sum, T.C. Low-temperature solution-processed wavelength-tunable perovskites for lasing. Nat. Mater. 2014, 13, 476. [CrossRef] [PubMed]

7. Lian, Z.; Yan, Q.; Gao, T.; Ding, J.; Lv, Q.; Ning, C.; Li, Q.; Sun, J.-L. Perovskite $\mathrm{CH}_{3} \mathrm{NH}_{3} \mathrm{PbI}_{3}(\mathrm{Cl})$ Single crystals: Rapid solution growth, unparalleled crystalline quality, and low trap density toward $10^{8} \mathrm{~cm}^{-3}$. J. Am. Chem. Soc. 2016, 138, 9409-9412. [CrossRef]

8. Zhang, Z.; Liang, Y.; Huang, H.; Liu, X.; Li, Q.; Chen, L.; Xu, D. Stable and highly efficient photocatalysis with lead-free double-perovskite of $\mathrm{Cs}_{2} \mathrm{AgBiBr}_{6}$. Angew. Chem. Int. Ed. 2019, 58, 7263-7267. [CrossRef]

9. Kojima, A.; Teshima, K.; Shirai, Y.; Miyasaka, T. Organometal halide perovskites as visible-light sensitizers for photovoltaic cells. J. Am. Chem. Soc. 2009, 131, 6050-6051. [CrossRef]

10. Kim, H.-S.; Lee, C.-R.; Im, J.-H.; Lee, K.-B.; Moehl, T.; Marchioro, A.; Moon, S.-J.; Humphry-Baker, R.; Yum, J.-H.; Moser, J.E. Lead iodide perovskite sensitized all-solid-state submicron thin film mesoscopic solar cell with efficiency exceeding 9\%. Sci. Rep. 2012, 2, 591. [CrossRef]

11. Liu, M.; Johnston, M.B.; Snaith, H.J. Efficient planar heterojunction perovskite solar cells by vapour deposition. Nature 2013, 501, 395. [CrossRef] [PubMed]

12. Zhou, H.; Chen, Q.; Li, G.; Luo, S.; Song, T.-B.; Duan, H.-S.; Hong, Z.; You, J.; Liu, Y.; Yang, Y. Interface engineering of highly efficient perovskite solar cells. Science 2014, 345, 542-546. [CrossRef] [PubMed]

13. Jeon, N.J.; Noh, J.H.; Yang, W.S.; Kim, Y.C.; Ryu, S.; Seo, J.; Seok, S.I. Compositional engineering of perovskite materials for high-performance solar cells. Nature 2015, 517, 476-480. [CrossRef] [PubMed]

14. Saliba, M.; Matsui, T.; Domanski, K.; Seo, J.-Y.; Ummadisingu, A.; Zakeeruddin, S.M.; Correa-Baena, J.-P.; Tress, W.R.; Abate, A.; Hagfeldt, A.; et al. Incorporation of rubidium cations into perovskite solar cells improves photovoltaic performance. Science 2016, 354, 206-209. [CrossRef]

15. Yang, W.S.; Park, B.-W.; Jung, E.H.; Jeon, N.J.; Kim, Y.C.; Lee, D.U.; Shin, S.S.; Seo, J.; Kim, E.K.; Noh, J.H.; et al. Iodide management in formamidinium-lead-halide-based perovskite layers for efficient solar cells. Science 2017, 356, 1376-1379. [CrossRef]

16. Jeon, N.J.; Na, H.; Jung, E.H.; Yang, T.-Y.; Lee, Y.G.; Kim, G.; Shin, H.-W.; Il Seok, S.; Lee, J.; Seo, J. A fluorene-terminated hole-transporting material for highly efficient and stable perovskite solar cells. Nat. Energy 2018, 3, 682-689. [CrossRef]

17. Jung, E.H.; Jeon, N.J.; Park, E.Y.; Moon, C.S.; Shin, T.J.; Yang, T.-Y.; Noh, J.H.; Seo, J. Efficient, stable and scalable perovskite solar cells using poly(3-hexylthiophene). Nature 2019, 567, 511-515. [CrossRef]

18. National Renewable Energy Laboratory. Best Research Cell Efficiencies. Available online: https: //www.nrel.gov/pv/assets/pdfs/best-research-cell-efficiencies.20191106.pdf\#opennewwindow (accessed on 22 January 2020).

19. Zhao, X.-G.; Yang, J.-H.; Fu, Y.; Yang, D.; Xu, Q.; Yu, L.; Wei, S.-H.; Zhang, L. Design of lead-free inorganic halide perovskites for solar cells via cation-transmutation. J. Am. Chem. Soc. 2017, 139, 2630-2638. [CrossRef]

20. Filip, M.R.; Hillman, S.; Haghighirad, A.A.; Snaith, H.J.; Giustino, F. Band gaps of the lead-free halide double perovskites $\mathrm{Cs}_{2} \mathrm{BiAgCl}_{6}$ and $\mathrm{Cs}_{2} \mathrm{BiAgBr}_{6}$ from theory and experiment. J. Phys. Chem. Lett. 2016, 7, 2579-2585. [CrossRef]

21. McClure, E.T.; Ball, M.R.; Windl, W.; Woodward, P.M. $\mathrm{Cs}_{2} \mathrm{AgBiX}_{6}(\mathrm{X}=\mathrm{Br}, \mathrm{Cl})$ : New visible light absorbing, lead-free halide perovskite semiconductors. Chem. Mater. 2016, 28, 1348-1354. [CrossRef]

22. Noel, N.K.; Stranks, S.D.; Abate, A.; Wehrenfennig, C.; Guarnera, S.; Haghighirad, A.-A.; Sadhanala, A.; Eperon, G.E.; Pathak, S.K.; Johnston, M.B. Lead-free organic-inorganic tin halide perovskites for photovoltaic applications. Energy Environ. Sci. 2014, 7, 3061-3068. [CrossRef] 
23. Roknuzzaman, M.; Ostrikov, K.K.; Wasalathilake, K.C.; Yan, C.; Wang, H.; Tesfamichael, T. Insight into lead-free organic-inorganic hybrid perovskites for photovoltaics and optoelectronics: A first-principles study. J. Org. Electron. 2018, 59, 99-106. [CrossRef]

24. Filip, M.R.; Giustino, F. Computational screening of homovalent lead substitution in organic-inorganic halide perovskites. J. Phys. Chem. C 2015, 120, 166-173. [CrossRef]

25. Körbel, S.; Marques, M.A.; Botti, S. Stability and electronic properties of new inorganic perovskites from high-throughput ab initio calculations. J. Mater. Chem. C 2016, 4, 3157-3167. [CrossRef]

26. Chu, L.; Ahmad, W.; Liu, W.; Yang, J.; Zhang, R.; Sun, Y.; Yang, J.; Li, X.A. Lead-free halide double perovskite materials: A new superstar toward green and stable optoelectronic applications. Nano-Micro Lett. 2019, 11, 16. [CrossRef]

27. Filip, M.R.; Volonakis, G.; Giustino, F. Hybrid halide perovskites: Fundamental theory and materials design. In Handbook of Materials Modeling: Applications: Current and Emerging Materials; Andreoni, W., Yip, S., Eds.; Springer International Publishing: Cham, Germany, 2018; pp. 1-30. [CrossRef]

28. Li, T.; Zhao, X.; Yang, D.; Du, M.-H.; Zhang, L. Intrinsic defect properties in halide double perovskites for optoelectronic applications. Phys. Rev. Appl. 2018, 10, 041001. [CrossRef]

29. Zhao, X.-G.; Yang, D.; Ren, J.-C.; Sun, Y.; Xiao, Z.; Zhang, L. Rational design of halide double perovskites for optoelectronic applications. Joule 2018, 2, 1662-1673. [CrossRef]

30. Li, Z.; Yin, W. Recent progress in Pb-free stable inorganic double halide perovskites. J. Semicond. 2018, 39, 071003. [CrossRef]

31. Xiao, Z.; Song, Z.; Yan, Y. From Lead Halide perovskites to lead-free metal halide perovskites and perovskite derivatives. Adv. Mater. 2019, 31, 1803792. [CrossRef]

32. Zhang, P.; Yang, J.; Wei, S.-H. Manipulation of cation combinations and configurations of halide double perovskites for solar cell absorbers. J. Mater. Chem. A 2018, 6, 1809-1815. [CrossRef]

33. Goldschmidt, V.M.J.N. Die gesetze der krystallochemie. Naturwissenschaften 1926, 14, 477-485. [CrossRef]

34. Li, C.; Lu, X.; Ding, W.; Feng, L.; Gao, Y.; Guo, Z. Formability of $\mathrm{ABX}_{3}(\mathrm{X}=\mathrm{F}, \mathrm{Cl}, \mathrm{Br}$, I) halide perovskites. Acta Crystallogr. B 2008, 64, 702-707. [CrossRef] [PubMed]

35. Ning, W.; Gao, F. Structural and functional diversity in lead-free halide perovskite materials. Adv. Mater. 2019, 31, 1900326. [CrossRef] [PubMed]

36. Teraoka, Y.; Wei, M.-D.; Kagawa, S. Double perovskites containing hexavalent molybdenum and tungsten: Synthesis, structural investigation and proposal of a fitness factor to discriminate the crystal symmetry. J. Mater. Chem. 1998, 8, 2323-2325. [CrossRef]

37. Lee, B.; Stoumpos, C.C.; Zhou, N.; Hao, F.; Malliakas, C.; Yeh, C.-Y.; Marks, T.J.; Kanatzidis, M.G.; Chang, R.P. Air-stable molecular semiconducting iodosalts for solar cell applications: $\mathrm{Cs}_{2} \mathrm{SnI}_{6}$ as a hole conductor. J. Am. Chem. Soc. 2014, 136, 15379-15385. [CrossRef]

38. Luo, J.; Wang, X.; Li, S.; Liu, J.; Guo, Y.; Niu, G.; Yao, L.; Fu, Y.; Gao, L.; Dong, Q.; et al. Efficient and stable emission of warm-white light from lead-free halide double perovskites. Nature 2018, 563, 541-545. [CrossRef]

39. Du, K.-Z.; Wang, X.; Han, Q.; Yan, Y.; Mitzi, D.B. Heterovalent B-site co-alloying approach for halide perovskite bandgap engineering. ACS Energy Lett. 2017, 2, 2486-2490. [CrossRef]

40. Karmakar, A.; Dodd, M.S.; Agnihotri, S.; Ravera, E.; Michaelis, V.K. Cu(II)-doped $\mathrm{Cs}_{2} \mathrm{SbAgCl}_{6}$ double perovskite: A lead-free, low-bandgap material. Chem. Mater. 2018, 30, 8280-8290. [CrossRef]

41. Liu, W.; Lin, Q.; Li, H.; Wu, K.; Robel, I.; Pietryga, J.M.; Klimov, V.I. Mn ${ }^{2+}$-doped lead halide perovskite nanocrystals with dual-color emission controlled by halide content. J. Am. Chem. Soc. 2016, 138, 14954-14961. [CrossRef]

42. Tan, Z.; Li, J.; Zhang, C.; Li, Z.; Hu, Q.; Xiao, Z.; Kamiya, T.; Hosono, H.; Niu, G.; Lifshitz, E. Highly efficient blue-emitting Bi-doped $\mathrm{Cs}_{2} \mathrm{SnCl}_{6}$ perovskite variant: Photoluminescence induced by impurity doping. Adv. Funct. Mater. 2018, 28, 1801131. [CrossRef]

43. Bagnall, K.; Laidler, J.; Stewart, M. Americium chloro-complexes. J. Chem. Soc. 1968, 133-136. [CrossRef]

44. Morss, L.R.; Siegal, M.; Stenger, L.; Edelstein, N. Preparation of cubic chloro complex compounds of trivalent metals: $\mathrm{Cs}_{2} \mathrm{NaMCl}_{6}$. Inorg. Chem. 1970, 9, 1771-1775. [CrossRef]

45. Morrs, L.; Robinson, W. Crystal structure of $\mathrm{Cs}_{2} \mathrm{NaBiCl}_{6}$. Acta Crystallogr. B 1972, 28, 653-654. [CrossRef]

46. Pelle, F.; Jacquier, B.; Denis, J.; Blanzat, B. Optical properties of $\mathrm{Cs}_{2} \mathrm{NaBiCl}_{6}$. J. Lumin. 1978, 17, 61-72. [CrossRef] 
47. Pelle, F.; Blanzat, B.; Chevalier, B. Low temperature phase transition in cubic elpasolithe crystal $\mathrm{Cs}_{2} \mathrm{NaBiCl}_{6}$. Solid State Commun. 1984, 49, 1089-1093. [CrossRef]

48. Majher, J.D.; Gray, M.B.; Strom, T.A.; Woodward, P.M. $\mathrm{Cs}_{2} \mathrm{NaBiCl}_{6}: \mathrm{Mn}^{2+}-\mathrm{A}$ new orange-red halide double perovskite phosphor. Chem. Mater. 2019, 31, 1738-1744. [CrossRef]

49. Slavney, A.H.; Hu, T.; Lindenberg, A.M.; Karunadasa, H.I. A bismuth-halide double perovskite with long carrier recombination lifetime for photovoltaic applications. J. Am. Chem. Soc. 2016, 138, 2138-2141. [CrossRef]

50. Pan, W.; Wu, H.; Luo, J.; Deng, Z.; Ge, C.; Chen, C.; Jiang, X.; Yin, W.-J.; Niu, G.; Zhu, L. Cs ${ }_{2} \mathrm{AgBiBr}_{6}$ single-crystal X-ray detectors with a low detection limit. Nat. Photonics 2017, 11, 726. [CrossRef]

51. Savory, C.N.; Walsh, A.; Scanlon, D.O. Can Pb-free halide double perovskites support high-efficiency solar cells? ACS Energy Lett. 2016, 1, 949-955. [CrossRef]

52. Saparov, B.; Sun, J.-P.; Meng, W.; Xiao, Z.; Duan, H.-S.; Gunawan, O.; Shin, D.; Hill, I.G.; Yan, Y.; Mitzi, D.B. Thin-film deposition and characterization of a Sn-deficient perovskite derivative $\mathrm{Cs}_{2} \mathrm{SnI}_{6}$. Chem. Mater. 2016, 28, 2315-2322. [CrossRef]

53. Schade, L.; Wright, A.D.; Johnson, R.D.; Dollmann, M.; Wenger, B.; Nayak, P.K.; Prabhakaran, D.; Herz, L.M.; Nicholas, R.; Snaith, H.J.; et al. Structural and optical properties of $\mathrm{Cs}_{2} \mathrm{AgBiBr}_{6}$ double perovskite. ACS Energy Lett. 2019, 4, 299-305. [CrossRef]

54. Lan, C.; Zhao, S.; Luo, J.; Fan, P. First-principles study of anion diffusion in lead-free halide double perovskites. Phys. Chem. Chem. Phys. 2018, 20, 24339-24344. [CrossRef] [PubMed]

55. Steele, J.A.; Puech, P.; Keshavarz, M.; Yang, R.; Banerjee, S.; Debroye, E.; Kim, C.W.; Yuan, H.; Heo, N.H.; Vanacken, J. Giant electron-phonon coupling and deep conduction band resonance in metal halide double perovskite. ACS Nano 2018, 12, 8081-8090. [CrossRef] [PubMed]

56. Kung, P.-K.; Li, M.-H.; Lin, P.-Y.; Jhang, J.-Y.; Pantaler, M.; Lupascu, D.C.; Grancini, G.; Chen, P. Lead-free double perovskites for perovskite solar cells. Solar RRL 2020. [CrossRef]

57. Hutter, E.M.; Gélvez-Rueda, M.C.; Bartesaghi, D.; Grozema, F.C.; Savenije, T.J. Band-like charge transport in $\mathrm{Cs}_{2} \mathrm{AgBiBr}_{6}$ and mixed antimony-bismuth $\mathrm{Cs}_{2} \mathrm{AgBi}_{1-\mathrm{x}} \mathrm{SbxBr}_{6}$ halide double perovskites. ACS Omega 2018, 3, 11655-11662. [CrossRef]

58. Du, K.-Z.; Meng, W.; Wang, X.; Yan, Y.; Mitzi, D.B. Bandgap engineering of lead-free double perovskite $\mathrm{Cs}_{2} \mathrm{AgBiBr}_{6}$ through trivalent metal alloying. Angew. Chem. Int. Ed. 2017, 56, 8158-8162. [CrossRef]

59. Vegard, L.J.Z.F.P. Die Konstitution der Mischkristalle und die Raumfüllung der Atome. Zeitschrift Für Physik 1921, 5, 17-26. [CrossRef]

60. Slavney, A.H.; Leppert, L.; Bartesaghi, D.; Gold-Parker, A.; Toney, M.F.; Savenije, T.J.; Neaton, J.B.; Karunadasa, H.I. Defect-induced band-edge reconstruction of a bismuth-halide double perovskite for visible-light absorption. J. Am. Chem. Soc. 2017, 139, 5015-5018. [CrossRef]

61. Volonakis, G.; Filip, M.R.; Haghighirad, A.A.; Sakai, N.; Wenger, B.; Snaith, H.J.; Giustino, F. Lead-free halide double perovskites via heterovalent substitution of noble metals. J. Phys. Chem. Lett. 2016, 7, 1254-1259. [CrossRef]

62. Wei, F.; Deng, Z.; Sun, S.; Hartono, N.T.P.; Seng, H.L.; Buonassisi, T.; Bristowe, P.D.; Cheetham, A.K. Enhanced visible light absorption for lead-free double perovskite $\mathrm{Cs}_{2} \mathrm{AgSbBr}_{6}$. Chem. Commun. 2019, 55, 3721-3724. [CrossRef]

63. Deng, W.; Deng, Z.-Y.; He, J.; Wang, M.; Chen, Z.-X.; Wei, S.-H.; Feng, H.-J. Synthesis of $\mathrm{Cs}_{2} \mathrm{AgSbCl}_{6}$ and improved optoelectronic properties of $\mathrm{Cs}_{2} \mathrm{AgSbCl}_{6} / \mathrm{TiO}_{2}$ heterostructure driven by the interface effect for lead-free double perovskites solar cells. Appl. Phys. Lett. 2017, 111, 151602. [CrossRef]

64. Volonakis, G.; Haghighirad, A.A.; Milot, R.L.; Sio, W.H.; Filip, M.R.; Wenger, B.; Johnston, M.B.; Herz, L.M.; Snaith, H.J.; Giustino, F. $\mathrm{Cs}_{2} \mathrm{InAgCl}_{6}$ : A new lead-free halide double perovskite with direct band gap. J. Phys. Chem. Lett. 2017, 8, 772-778. [CrossRef] [PubMed]

65. Tran, T.T.; Panella, J.R.; Chamorro, J.R.; Morey, J.R.; McQueen, T.M. Designing indirect-direct bandgap transitions in double perovskites. Mater. Horiz. 2017, 4, 688-693. [CrossRef]

66. Hutter, E.M.; Gélvez-Rueda, M.C.; Osherov, A.; Bulović, V.; Grozema, F.C.; Stranks, S.D.; Savenije, T.J. Direct-indirect character of the bandgap in methylammonium lead iodide perovskite. Nat. Mater. 2017, 16, 115. [CrossRef] [PubMed] 
67. Zhou, J.; Xia, Z.; Molokeev, M.S.; Zhang, X.; Peng, D.; Liu, Q. Composition design, optical gap and stability investigations of lead-free halide double perovskite $\mathrm{Cs}_{2} \mathrm{AgInCl}_{6}$. J. Mater. Chem. A 2017, 5, 15031-15037. [CrossRef]

68. Luo, J.; Li, S.; Wu, H.; Zhou, Y.; Li, Y.; Liu, J.; Li, J.; Li, K.; Yi, F.; Niu, G.; et al. Cs $2 \mathrm{AgInCl}_{6}$ double perovskite single crystals: Parity forbidden transitions and their application for sensitive and fast UV photodetectors. ACS Photonics 2018, 5, 398-405. [CrossRef]

69. Weng, W.Y.; Chang, S.J.; Hsu, C.L.; Hsueh, T.J. A ZnO-nanowire phototransistor prepared on glass substrates. ACS Appl. Mater. Interfaces 2011, 3, 162-166. [CrossRef]

70. Nag, A. Synthesis and luminescence of Mn-doped $\mathrm{Cs}_{2} \mathrm{AgInCl}_{6}$ double perovskites. Chem. Commun. 2018, 54, 5205-5208.

71. Nie, X.; Wei, S.-H.; Zhang, S. Bipolar doping and band-gap anomalies in delafossite transparent conductive oxides. Phys. Rev. Lett. 2002, 88, 066405. [CrossRef]

72. Walsh, A.; Da Silva, J.L.; Wei, S.-H.; Körber, C.; Klein, A.; Piper, L.; DeMasi, A.; Smith, K.E.; Panaccione, G.; Torelli, P. Nature of the band gap of $\operatorname{In}_{2} \mathrm{O}_{3}$ revealed by first-principles calculations and x-ray spectroscopy. Phys. Rev. Lett. 2008, 100, 167402. [CrossRef]

73. Kehoe, A.B.; Scanlon, D.O.; Watson, G.W. Nature of the band gap of $\mathrm{Tl}_{2} \mathrm{O}_{3}$. Phys. Rev. B 2011, 83, 233202. [CrossRef]

74. Summitt, R.; Marley, J.A.; Borrelli, N.F. The ultraviolet absorption edge of stannic oxide $\left(\mathrm{SnO}_{2}\right)$. J. Phys. Chem. Solids 1964, 25, 1465-1469. [CrossRef]

75. Meng, W.; Wang, X.; Xiao, Z.; Wang, J.; Mitzi, D.B.; Yan, Y. Parity-forbidden transitions and their impact on the optical absorption properties of lead-free metal halide perovskites and double perovskites. J. Phys. Chem. Lett. 2017, 8, 2999-3007. [CrossRef] [PubMed]

76. Slavney, A.H.; Leppert, L.; Saldivar Valdes, A.; Bartesaghi, D.; Savenije, T.J.; Neaton, J.B.; Karunadasa, H.I. Small-band-gap halide double perovskites. Angew. Chem. Int. Ed. 2018, 57, 12765-12770. [CrossRef] [PubMed]

77. Cao, X.; Kang, L.; Guo, S.; Zhang, M.; Lin, Z.; Gao, J. $\mathrm{Cs}_{2} \mathrm{NaVCl}_{6}$ : A Pb-free halide double perovskite with strong visible and near-infrared light absorption. ACS Appl. Mater. Interfaces 2019, 11, 38648-38653. [CrossRef]

78. Deng, Z.; Wei, F.; Sun, S.; Kieslich, G.; Cheetham, A.K.; Bristowe, P.D. Exploring the properties of lead-free hybrid double perovskites using a combined computational-experimental approach. J. Mater. Chem. A 2016, 4, 12025-12029. [CrossRef]

79. Slavney, A.H.; Connor, B.A.; Leppert, L.; Karunadasa, H.I. A pencil-and-paper method for elucidating halide double perovskite band structures. Chem. Sci. 2019, 10, 11041-11053. [CrossRef]

80. Wei, F.; Deng, Z.; Sun, S.; Xie, F.; Kieslich, G.; Evans, D.M.; Carpenter, M.A.; Bristowe, P.D.; Cheetham, A.K. The synthesis, structure and electronic properties of a lead-free hybrid inorganic-organic double perovskite $(\mathrm{MA})_{2} \mathrm{KBiCl}_{6}(\mathrm{MA}=$ methylammonium). Mater. Horiz. 2016, 3, 328-332. [CrossRef]

81. Li, Y.-J.; Wu, T.; Sun, L.; Yang, R.-X.; Jiang, L.; Cheng, P.-F.; Hao, Q.-Q.; Wang, T.-J.; Lu, R.-F.; Deng, W.-Q. Lead-free and stable antimony-silver-halide double perovskite $\left(\mathrm{CH}_{3} \mathrm{NH}_{3}\right)_{2} \mathrm{AgSbI}$. RSC Adv. 2017, 7, 35175-35180. [CrossRef]

82. Volonakis, G.; Haghighirad, A.A.; Snaith, H.J.; Giustino, F. Route to stable lead-free double perovskites with the electronic structure of $\mathrm{CH}_{3} \mathrm{NH}_{3} \mathrm{PbI}_{3}$ : A case for mixed-cation $\left[\mathrm{Cs} / \mathrm{CH}_{3} \mathrm{NH}_{3} / \mathrm{CH}\left(\mathrm{NH}_{2}\right)_{2}\right]_{2} \mathrm{InBiBr}_{6}$. J. Phys. Chem. Lett. 2017, 8, 3917-3924. [CrossRef]

83. Mao, L.; Teicher, S.M.L.; Stoumpos, C.C.; Kennard, R.M.; DeCrescent, R.A.; Wu, G.; Schuller, J.A.; Chabinyc, M.L.; Cheetham, A.K.; Seshadri, R. Chemical and structural diversity of hybrid layered double perovskite halides. J. Am. Chem. Soc. 2019, 141, 19099-19109. [CrossRef] [PubMed]

84. Tang, G.; Xiao, Z.; Hong, J. Designing two-dimensional properties in three-dimensional halide perovskites via orbital engineering. J. Phys. Chem. Lett. 2019, 10, 6688-6694. [CrossRef] [PubMed]

85. Connor, B.A.; Leppert, L.; Smith, M.D.; Neaton, J.B.; Karunadasa, H.I. Layered halide double perovskites: Dimensional reduction of $\mathrm{Cs}_{2} \mathrm{AgBiBr}_{6}$. J. Am. Chem. Soc. 2018, 140, 5235-5240. [CrossRef] [PubMed]

86. Xu, Z.; Liu, X.; Li, Y.; Liu, X.; Yang, T.; Ji, C.; Han, S.; Xu, Y.; Luo, J.; Sun, Z. Exploring lead-free hybrid double perovskite crystals of $(\mathrm{BA})_{2} \mathrm{CsAgBiBr}_{7}$ with large mobility-lifetime product toward X-Ray detection. Angew. Chem. Int. Ed. 2019, 58, 15757-15761. [CrossRef] 
87. Fang, Y.; Zhang, L.; Wu, L.; Yan, J.; Lin, Y.; Wang, K.; Mao, W.L.; Zou, B. Pressure-induced emission (PIE) and phase transition of a two-dimensional halide double perovskite $(\mathrm{BA})_{4} \mathrm{AgBiBr} 8\left(\mathrm{BA}=\mathrm{CH}_{3}\left(\mathrm{CH}_{2}\right)_{3} \mathrm{NH}_{3}{ }^{+}\right)$. Angew. Chem. Int. Ed. 2019, 58, 15249-15253. [CrossRef]

88. Bi, L.-Y.; Hu, Y.-Q.; Li, M.-Q.; Hu, T.-L.; Zhang, H.-L.; Yin, X.-T.; Que, W.-X.; Lassoued, M.S.; Zheng, Y.-Z. Two-dimensional lead-free iodide-based hybrid double perovskites: Crystal growth, thin-film preparation and photocurrent responses. J. Mater. Chem. A 2019, 7, 19662-19667. [CrossRef]

89. Swarnkar, A.; Ravi, V.K.; Nag, A. Beyond colloidal cesium lead halide perovskite nanocrystals: Analogous metal halides and doping. ACS Energy Lett. 2017, 2, 1089-1098. [CrossRef]

90. Zhou, L.; Xu, Y.F.; Chen, B.X.; Kuang, D.B.; Su, C.Y. Synthesis and photocatalytic application of stable lead-free $\mathrm{Cs}_{2} \mathrm{AgBiBr}_{6}$ perovskite nanocrystals. Small 2018, 14, 1703762. [CrossRef]

91. Creutz, S.E.; Crites, E.N.; De Siena, M.C.; Gamelin, D.R. Colloidal nanocrystals of lead-free double-perovskite (elpasolite) semiconductors: Synthesis and anion exchange to access new materials. Nano Lett. 2018, 18, 1118-1123. [CrossRef]

92. Bekenstein, Y.; Dahl, J.C.; Huang, J.; Osowiecki, W.T.; Swabeck, J.K.; Chan, E.M.; Yang, P.; Alivisatos, A.P. The making and breaking of lead-free double perovskite nanocrystals of cesium silver-bismuth halide compositions. Nano Lett. 2018, 18, 3502-3508. [CrossRef]

93. Lignos, I.; Stavrakis, S.; Nedelcu, G.; Protesescu, L.; deMello, A.J.; Kovalenko, M.V. Synthesis of cesium lead halide perovskite nanocrystals in a droplet-based microfluidic platform: Fast parametric space mapping. Nano Lett. 2016, 16, 1869-1877. [CrossRef] [PubMed]

94. Brittman, S.; Luo, J. A promising beginning for perovskite nanocrystals: A Nano Letters virtual issue. Nano Lett. 2018, 18, 2747-2750. [CrossRef] [PubMed]

95. Mir, W.J.; Jagadeeswararao, M.; Das, S.; Nag, A. Colloidal Mn-doped cesium lead halide perovskite nanoplatelets. ACS Energy Lett. 2017, 2, 537-543. [CrossRef]

96. Shamsi, J.; Urban, A.S.; Imran, M.; De Trizio, L.; Manna, L. Metal halide perovskite nanocrystals: Synthesis, post-synthesis modifications, and their optical properties. Chem. Rev. 2019, 119, 3296-3348. [CrossRef]

97. Yang, B.; Mao, X.; Hong, F.; Meng, W.; Tang, Y.; Xia, X.; Yang, S.; Deng, W.; Han, K. Lead-free direct band gap double-perovskite nanocrystals with bright-color emission. J. Am. Chem. Soc. 2018, 140, 17001-17006. [CrossRef]

98. Yang, B.; Chen, J.; Yang, S.; Hong, F.; Sun, L.; Han, P.; Pullerits, T.; Deng, W.; Han, K. Lead-free silver-bismuth halide double perovskite nanocrystals. Angew. Chem. Int. Ed. 2018, 57, 5359-5363. [CrossRef]

99. Hao, F.; Stoumpos, C.C.; Cao, D.H.; Chang, R.P.; Kanatzidis, M.G. Lead-free solid-state organic-inorganic halide perovskite solar cells. Nat. Photonics 2014, 8, 489. [CrossRef]

100. Pantaler, M.; Cho, K.T.; Queloz, V.I.E.; García Benito, I.; Fettkenhauer, C.; Anusca, I.; Nazeeruddin, M.K.; Lupascu, D.C.; Grancini, G. Hysteresis-free lead-free double-perovskite solar cells by interface engineering. ACS Energy Lett. 2018, 3, 1781-1786. [CrossRef]

101. Zhang, J.; Bai, D.; Jin, Z.; Bian, H.; Wang, K.; Sun, J.; Wang, Q.; Liu, S. 3D-2D-0D interface profiling for record efficiency all-inorganic $\mathrm{CsPbBrI}_{2}$ perovskite solar cells with superior stability. Adv. Energy Mater. 2018, 8, 1703246. [CrossRef]

102. Greul, E.; Petrus Michiel, L.; Binek, A.; Docampo, P.; Bein, T. Highly stable, phase pure $\mathrm{Cs}_{2} \mathrm{AgBiBr}_{6} \mathrm{double}$ perovskite thin films for optoelectronic applications. J. Mater. Chem. A 2017, 5, 19972-19981. [CrossRef]

103. Volonakis, G.; Giustino, F. Surface properties of lead-free halide double perovskites: Possible visible-light photo-catalysts for water splitting. Appl. Phys. Lett. 2018, 112, 243901. [CrossRef]

104. Zhao, L.; Kerner, R.A.; Xiao, Z.; Lin, Y.L.; Lee, K.M.; Schwartz, J.; Rand, B.P. Redox chemistry dominates the degradation and decomposition of metal halide perovskite optoelectronic devices. ACS Energy Lett. 2016, 1, 595-602. [CrossRef]

105. Tiong, V.T.; Pham, N.D.; Wang, T.; Zhu, T.; Zhao, X.; Zhang, Y.; Shen, Q.; Bell, J.; Hu, L.; Dai, S. Octadecylamine-functionalized single-walled carbon nanotubes for facilitating the formation of a monolithic perovskite layer and stable solar cells. Adv. Funct. Mater. 2018, 28, 1705545. [CrossRef]

(C) 2020 by the authors. Licensee MDPI, Basel, Switzerland. This article is an open access article distributed under the terms and conditions of the Creative Commons Attribution (CC BY) license (http://creativecommons.org/licenses/by/4.0/). 